\title{
Mechanism of Intestinal Flora and Proteomics on Regulating Immune Function of Durio zibethinus Rind Polysaccharide
}

\author{
Huimin Jiang $\mathbb{D}^{1},{ }^{1}$ Jinmei Wang $\mathbb{D}^{1,2}$ Qiongxin Liang ${ }^{10},{ }^{1}$ Shengjun Jiang $\left(\mathbb{D},{ }^{1}\right.$ \\ Changyang Ma $\left(\mathbb{0},{ }^{1,3}\right.$ Yan Zhang $\left({ }^{1},{ }^{4}\right.$ and Wenyi Kang $\left(\mathbb{1}^{1,2,3}\right.$ \\ ${ }^{1}$ National R\&D Center for Edible Fungus Processing Technology, Henan University, Kaifeng, 475004 Henan Province, China \\ ${ }^{2}$ Joint International Research Laboratory of Food \& Medicine Resource Function, Henan University, Kaifeng, \\ 475004 Henan Province, China \\ ${ }^{3}$ Functional Food Engineering Technology Research Center, Henan University, Kaifeng, 475004 Henan Province, China \\ ${ }^{4}$ College of Forensic Medicine, Hebei Medical University, Shijiazhuang 050017, China
}

Correspondence should be addressed to Changyang Ma; macaya1024@sina.com, Yan Zhang; snowwinglv@126.com, and Wenyi Kang; kangweny@hotmail.com

Received 17 November 2020; Revised 20 December 2020; Accepted 22 January 2021; Published 2 February 2021

Academic Editor: Daoud Ali

Copyright (c) 2021 Huimin Jiang et al. This is an open access article distributed under the Creative Commons Attribution License, which permits unrestricted use, distribution, and reproduction in any medium, provided the original work is properly cited.

\begin{abstract}
In this study, cyclophosphamide was injected intraperitoneally to establish an immunosuppressive mouse model to study the immune regulating effects of Durio zibethinus Murr rind polysaccharide (DZMP) through proteomics and intestinal flora. The results showed that the thymus and spleen indexes of the high-dose DZMP $(200 \mathrm{mg} / \mathrm{kg})$ group were significantly increased, and the tissue structure of the spleen was improved compared with the model group $(P<0.01)$. The contents of IL-2, IL-4, IL-6, and TNF- $\alpha$ in the high-dose group of DZMP were significantly increased $(P<0.001)$. Activities of acid phosphatase (ACP), lactate dehydrogenase (LDH), superoxide dismutase (SOD), and total antioxidant capacity (T-AOC) were increased in serum $(P<0.01)$. In the liver, catalase $(\mathrm{CAT})$ activity was increased $(P<0.001)$ while the malondialdehyde $(\mathrm{MDA})$ content was decreased and immune activity was increased $(P<0.001)$. Proteomics studies showed that the drug group could significantly increase the low-affinity immunoglobulin gamma Fc receptor III $(\mathrm{Fc} \gamma \mathrm{RIII})$ protein and protein kinase $\mathrm{C}-\alpha(\mathrm{PKC}-\alpha)$ compared with the model group $(P<0.001)$. In addition, the result showed that those proteins were likely involved in the regulation of the metabolic pathways of autoimmune thyroid disease, Staphylococcus aureus infection, and NF- $\kappa$ B signaling pathway. Intestinal microbial studies showed that shortchain fatty acid (SCFA) content was increased as well as the relative abundance of beneficial bacteria Akkermansia, Bacteroides, and Paraprevotella, while the relative abundance of Ruminococcus and Oscillospira was decreased compared with the model group $(P<0.001)$. The results showed that DZMP might play a beneficial role in immune regulation by improving intestinal flora.
\end{abstract}

\section{Introduction}

The immune system consists of immune organs, immune cells, and immune molecules [1]. The immune system's stress response to external stimuli is considered as one of the important defense strategies for the human body to prevent and fight against foreign infections, inflammation, and cancer $[2,3]$. Studies have shown that the main immunomodulatory mechanism of polysaccharides is to help the host form a strong immune response by activating the host's immune response $[4,5]$. Previous studies showed that polysaccharide from
Ganoderma atrum could significantly improve the immune organ index [6], Epimedium brevicornu Maxim polysaccharides could play an important role as immune adjuvant [7], and Malus halliana Koehne flower polysaccharide can regulate the content of cytokines and enhance the immune function of immunosuppressed mice [8].

Intestinal flora belongs to a complex microecosystem, which involves microbial interaction, nutrient metabolism, immune function, and diseases $[9,10]$. The metabolism of the intestinal microbial community is closely related to the health of the host, among which beneficial bacteria can 
regulate the absorption and utilization of nutrients in the intestinal tract $[11,12]$. In some disease areas, such as cancer, colitis, and obesity, the adjuvant therapy of beneficial bacteria plays a good regulatory role [13]. Besides, existing studies showed that Fructus morji pectin polysaccharide and its metabolites have beneficial effects on health by regulating the growth of intestinal beneficial bacteria Bacteroides taiotaomicron [14]. Short-chain fatty acids (SCFAs) are key factors to regulate the intestinal flora [15]. Studies showed that SCFAs had important biological functions, including maintaining energy; adjusting colon and intracellular $\mathrm{pH}$; and regulating cell ion transport, proliferation, and gene expression differentiation [16]. The concentration of SCFAs in the cecum and colonic cavity can be significantly changed by high-dose administration of Pleurotus eryngii polysaccharide, and the gastrointestinal function can be regulated [17].

In these studies, many omics techniques such as proteome, genome, and transcriptome have been used to study the action mechanism of some natural products on diseases. Proteomics technology focuses on the differences in the expression level, quantity, and modification status of proteomics among different experimental groups to identify the specific proteins, which are related to disease diagnosis and protein targets of drug therapy [18-21]. Wang et al. performed 2D-DIGE gel electrophoresis analysis on the liver proteins of mice from the normal group and the experimental group administrated with the Dendrobium huoshanense polysaccharide, and identified 18 differentially expressed proteins involved in glucose metabolism, amino acid metabolism, and other metabolic pathways [22]. Chao et al. compared the protein expression profiles related to the proliferation of mouse spleen monocytes before and after the effect of total polysaccharide from Ganoderma spore, and found out the target proteins with the functions of cell survival and proliferation, cell activation and migration, and cytoskeleton structure [23]. Wei et al. studied the Hedysarum polybotrys polysaccharide on the immune function of mice at the level of proteomics, and found out its significant improvement effect on the protein expression profile of thymus cells and the relationship of protein synthesis initiation factor 4, carbolic anhydrase, reductase 6, and proteasome with the thymus immune regulation in mice [24].

Cyclophosphamide (CTX), one immunosuppressive agent in the clinic, is usually taken as a common chemotherapy drug to decrease spleen index, lymphocyte proliferation, and phagocytic cell activity [25]. At the same time, polysaccharides are commonly used to improve the side effects caused by this chemotherapy drug. For example, in the treatment of intestinal tumor mice, carboxymethyl polysaccharide can alleviate the adverse effects of chemotherapy drugs and enhance the immunity of mice [26]. In addition, Astragalus polysaccharide, Panax ginseng polysaccharide, Lentinula edodes polysaccharide, and Ganoderma lucidum polysaccharide have been widely used as adjuvant drugs in cancer treatment.

The D. zibethinus rind is the husk of durian in Bombacaceae, and current researches mainly focus on its surface chemistry and adsorption function [27, 28]. Pharmacological studies show that durian skin extract has cough-relieving, bowel laxative, analgesic, antioxidant, and antibacterial activities [29-31]. Studies on the chemistry of DZMP mainly focus on flavonoids. The results of our preexperiment found that DZMP had an immunomodulatory effect.

Thus, in this paper, proteomics and intestinal flora were used to investigate the immune effect of DZMP on an immunosuppressed mouse model in vivo.

\section{Materials and Methods}

2.1. Materials and Chemicals. CTX (batch number: 19012825) was purchased from Jiangsu Hengrui Pharmaceutical Co., Ltd. Lentinula edodes polysaccharide tablets (batch number: 1903010) was from Hubei Guangren Pharmaceutical Co., Ltd. D. zibethinus rind was collected from supermarkets in Kaifeng City, Henan Province, and identified by Professor Changqin Li of The National Center for Edible Fungus Processing Technology, Henan University. Then, the D. zibethinus rind was chopped, dried, and used to extract the DZMP following the procedure from a previous research [30].

2.2. Animal Experimental Design. A total of 60 SPF Kunming mice (male, 20 22 g) were purchased from Henan Provincial Laboratory Animal Center with the following license number: SCXK (Yu) 2017-0004. Before the experiment, these mice were allowed to acclimate for 1 week (temperature: $25^{\circ} \mathrm{C} \pm 2^{\circ} \mathrm{C}$, lighting: $12 \mathrm{~h}$ light $/ 12 \mathrm{~h}$ dark, and humidity: $40 \% \sim 45 \%$ ) before the experiment.

These mice were randomly divided into 6 groups: the blank group (BC), the model group (MC), the positive control group (PC), the DZMP high-dose group (HD), the DZMP medium-dose group (MD), and the DZMP lowdose group (LD) (with 10 mice in each group).

The $\mathrm{BC}$ and $\mathrm{MC}$ groups were given normal saline at $0.1 \mathrm{~mL} / 10 \mathrm{~g} \mathrm{BW}$ every day. In the PC group, Lentinula polysaccharide tablet, one common immunosuppression modulator in the clinic, was administered at $3 \mathrm{mg} / \mathrm{kg} \mathrm{BW}$ by oral gavage. The $\mathrm{HD}, \mathrm{MD}$, and $\mathrm{LD}$ groups were given DZMP orally at 200,100 , and $50 \mathrm{mg} / \mathrm{kg} \mathrm{BW}$, respectively, once a day. All groups were treated for 21 days as described above. On the 18th, 19th, 20th, and 21st days, the BC group was intraperitoneally injected with normal saline, while the other groups were modeled by intraperitoneally injecting with CTX at $70 \mathrm{mg} / \mathrm{kg} \mathrm{BW}$.

2.3. Sample Collection. After treatments, the rats were weighed and fasted overnight (12-14h). Blood was taken from the eyeball, placed for $30 \mathrm{~min}$, centrifuged at $3500 \mathrm{~g}$ for $10 \mathrm{~min}$, and then the serum was collected from the supernatant and stored at $-20^{\circ} \mathrm{C}$ until analyzed. The spleen and thymus were taken and weighed for the organ index. Partial spleens of mice were cut and rinsed with PBS for the antioxidant capacity of this organ. The livers of each mouse were cut and stored at $-80^{\circ} \mathrm{C}$ for later use in proteomics research. The cecum of each mouse was removed, $0.3 \mathrm{~g}$ of cecal contents were placed in a $4 \mathrm{~mL}$ centrifuge tube, and then the samples were stored at $-40^{\circ} \mathrm{C}$ for SCFA determination. To determine the bacterial flora, the cecal contents of 3 mice in each cage were collected randomly and a total of 18 samples 
TABLE 1: Chromatographic elution conditions.

\begin{tabular}{|c|c|c|c|c|c|c|}
\hline Time/min & $0-5$ & $5-45$ & $45-50$ & $50-52$ & $52-54$ & $54-60$ \\
\hline Mobile phase A ( $2 \%$ acetonitrile, $0.1 \%$ formic acid) & $95 \%$ & $75 \%$ & $65 \%$ & $20 \%$ & $20 \%$ & $95 \%$ \\
\hline Mobile phase B ( $98 \%$ acetonitrile, $0.1 \%$ formic acid) & $5 \%$ & $25 \%$ & $35 \%$ & $80 \%$ & $80 \%$ & $5 \%$ \\
\hline
\end{tabular}

were stored at $-80^{\circ} \mathrm{C}$ until $(0.2 \mathrm{~g} / \mathrm{sample})$ taken for DNA extraction.

2.4. Thymus Index and Spleen Index. The spleen and thymus were taken, cleaned, and weighed. Spleen and thymus indexes were calculated according to the following formulas:

$$
\begin{gathered}
\text { Thymus index }=\frac{\text { thymus weight }(\mathrm{mg})}{\text { body weight }(10 \mathrm{~g})}, \\
\text { Spleen index }=\frac{\text { spleen weight }(\mathrm{mg})}{\text { body weight }(10 \mathrm{~g})} .
\end{gathered}
$$

2.5. Determination of Cytokine Content. The contents of IL-2, IL-4, IL-6, and TNF- $\alpha$ were determined by ELISA kits.

2.6. Determination of Antioxidant Stress Ability. About $50 \mathrm{mg}$ of spleen was taken for tissue homogenization, and MDA content and CAT activity were, respectively, detected according to the kit instructions. The activities of SOD and T-AOC were examined according to the instructions of the kit. The activity values of lactate dehydrogenase (LDH) and acid phosphatase (ACP) were determined by microenzyme labeling and microplate method according to the instructions of the corresponding kits, respectively.

2.7. Histological Evaluation. The thymus and spleen parts of mice were rinsed and placed in $4 \%$ paraformaldehyde solution for $24 \mathrm{~h}$. After that, they were dehydrated, embedded in conventional paraffin, and sliced. Hematoxylin-eosin staining was performed to the tissue slice for $5 \mathrm{~min}$, and then dehydration was conducted. The slices were sealed with neutral gum.

2.8. Proteomics Research. From the BC, MC, and HD groups, 9 mice were randomly selected from each group for their livers. The liver tissues of every 3 mice were combined together as one sample, and a total of 9 samples were obtained for proteomics research.

2.8.1. Protein Extraction. The protein extraction procedure is as follows: take $300-500 \mathrm{mg}$ of the liver tissue, add two steel balls and lysate, place it on ice for $5 \mathrm{~min}$, and add dithiothreitol (DTT). Then, break and crack the tissue using a grinding apparatus (power: $60 \mathrm{~Hz}$, time: $2 \mathrm{~min}$ ). After that, centrifuge it at $25000 \mathrm{~g}$ and $4^{\circ} \mathrm{C}$ for $15 \mathrm{~min}$, and take the supernatant. Keep on adding DTT, iodoacetamide, cold acetone, and sodium dodecyl sulfate L3 (SDSL3) in turn to extract the protein and repeat the centrifugation. The protein solution would then be obtained from the supernatant. Take $30 \mu \mathrm{g}$ protein solution from each sample to determine the protein concentration by the SDS-PAGE method.
TABLE 2: Effects of DZMP on immune organs in mice $(n=10)$.

\begin{tabular}{lcc}
\hline Groups & Thymus index $(\mathrm{mg} / 10 \mathrm{~g})$ & Spleen index $(\mathrm{mg} / 10 \mathrm{~g})$ \\
\hline BC & $24.72 \pm 4.47$ & $20.89 \pm 4.36$ \\
MC & $6.40 \pm 0.98^{* * *}$ & $8.87 \pm 1.33^{* * *}$ \\
PC & $9.74 \pm 2.05^{\# \#}$ & $11.87 \pm 1.88^{\# \#}$ \\
HD & $9.07 \pm 2.07^{\#}$ & $12.55 \pm 1.97^{\# \#}$ \\
MD & $6.59 \pm 0.91$ & $10.87 \pm 1.94$ \\
LD & $6.57 \pm 1.32$ & $10.06 \pm 0.83$ \\
\hline
\end{tabular}

Compared with the BC group: ${ }^{* * *} P<0.001,{ }^{* *} P<0.01$, and ${ }^{*} P<0.05$. Compared with the MC group: ${ }^{\# \# \#} P<0.001,{ }^{\# \#} P<0.01$, and ${ }^{\#} P<0.05$.

2.8.2. Proteolysis. $100 \mu$ g protein solution was added into a $1.5 \mathrm{~mL}$ centrifuge tube. Dilute it with $0.5 \mathrm{M}$ triethyl ammonium bicarbonate (TEAB) until the final sodium dodecyl sulfate (SDS) concentration in the protein solution was lower than $0.1 \%$. Add this into the solution of trypsin enzyme with a $1: 20$ proportion of enzyme $(\mu \mathrm{g})$ and substrate protein $(\mu \mathrm{g})$. After vortex oscillation, centrifuge it at low speed for $1 \mathrm{~min}$ and incubate it at $37^{\circ} \mathrm{C}$ for $2 \mathrm{~h}$. After desalting the digested peptide and freeze-drying it, the target peptides would be obtained.

2.8.3. Peptide Labeling and Separation. Each tube with $2 \mathrm{mg}$ isobaric tag (IBT) reagent was dissolved with $80 \mu \mathrm{L}$ isopropanol and shaken for more than 1 min to fully dissolve. After enzymatic digestion and desalination, the peptide was dissolved in $0.2 \mathrm{M} \mathrm{TEAB}$ solution at a concentration of $4 \mu \mathrm{g} / \mu \mathrm{L}$ and shaken for more than $1 \mathrm{~min}$ to dissolve the peptide adequately. $100 \mu \mathrm{g}$ of peptide and $80 \mu \mathrm{L}$ of IBT reagent were rapidly mixed and centrifuged, and the $\mathrm{pH}$ value should be between 7.0 and 8.0. The peptide labeling operation was repeated for each channel of IBT reagent, and each of them was marked. Then, they were placed at room temperature for $2 \mathrm{~h}$ to let the peptide label sufficiently. The Shimadzu LC-20AB liquid phase system was used to separate peptides of the samples through a Gemini C18 column $(5 \mu \mathrm{m}, 4.6 \times$ $250 \mathrm{~mm})$.

2.8.4. LC Analysis. The extracted peptide samples were redissolved in mobile phase A ( $2 \%$ acetonitrile, $0.1 \%$ formic acid), centrifuged at $20,000 \mathrm{~g}$ for $10 \mathrm{~min}$, and the supernatant was taken for sample injection. Separation was performed using the Thermo UltiMate 3000 UHPLC. The samples were first enriched and desalted in a trap column, followed by a series separation with a self-loaded C18 column $(75 \mu \mathrm{m}$ inner diameter, $>3 \mu \mathrm{m}$ particle diameter, and $25 \mu \mathrm{m}$ column length) in a series with an effective gradient elution procedure at a flow rate of $300 \mathrm{~nL} / \mathrm{min}$ (Table 1). One mass spectrometer was located at the end of the nanoliquid phase separation process. 
TABLE 3: Effects of DZMP on the content of cytokines $(n=10)$.

\begin{tabular}{lcccc}
\hline Groups & IL-2 $(\mathrm{ng} / \mathrm{mL})$ & IL-4 $(\mathrm{pg} / \mathrm{mL})$ & IL-6 $(\mathrm{pg} / \mathrm{mL})$ & TNF- $\alpha(\mathrm{pg} / \mathrm{mL})$ \\
\hline BC & $2.67 \pm 0.77$ & $420.23 \pm 51.51$ & $78.93 \pm 7.75$ & $73.12 \pm 11.18$ \\
MC & $1.78 \pm 0.08^{* * *}$ & $341.23 \pm 17.90^{* * *}$ & $69.19 \pm 3.82^{* *}$ & $36.44 \pm 9.06^{* * *}$ \\
PC & $2.66 \pm 0.06^{\# \# \#}$ & $412.05 \pm 47.39^{\# \#}$ & $79.48 \pm 6.56^{\# \#}$ & $86.40 \pm 2.39^{\# \# \#}$ \\
HD & $2.63 \pm 0.14^{\# \# \#}$ & $392.63 \pm 49.26^{\#}$ & $79.49 \pm 6.48^{\# \#}$ & $99.83 \pm 13.05^{\# \# \#}$ \\
MD & $2.51 \pm 0.12^{\# \# \#}$ & $270.50 \pm 35.41^{\# \#}$ & $81.70 \pm 6.92^{\# \# \#}$ & $55.31 \pm 8.90^{\# \# \#}$ \\
LD & $2.42 \pm 0.07^{\# \#}$ & $274.37 \pm 52.58^{\# \#}$ & $73.51 \pm 7.96$ & $51.08 \pm 5.25^{\# \#}$ \\
\hline
\end{tabular}

Compared with the BC group: ${ }^{* *} P<0.001,{ }^{* *} P<0.01$, and ${ }^{*} P<0.05$. Compared with the MC group: ${ }^{\# \# \#} P<0.001$, ${ }^{\# \#} P<0.01$, and ${ }^{\#} P<0.05$.

TABLE 4: Effect of DZMP on serum ACP and LDH activities $(n=10)$.

\begin{tabular}{lcc}
\hline Groups & ACP (unit/100 mL) & LDH (U/L) \\
\hline BC & $8.89 \pm 0.95$ & $1580.44 \pm 72.08$ \\
MC & $4.01 \pm 0.69^{* * *}$ & $1468.21 \pm 42.44^{* *}$ \\
PC & $6.75 \pm 0.82^{\# \# \#}$ & $1451.51 \pm 79.53$ \\
HD & $6.95 \pm 1.20^{\# \# \#}$ & $1560.86 \pm 73.42^{\#}$ \\
MD & $5.35 \pm 1.09^{\# \#}$ & $1541.97 \pm 69.12^{\#}$ \\
LD & $5.61 \pm 1.01^{\# \#}$ & $1448.96 \pm 113.31$ \\
\hline
\end{tabular}

Compared with the normal group: ${ }^{* * *} P<0.001,{ }^{* *} P<0.01$, and ${ }^{*} P<0.05$. Compared with the model group: ${ }^{\# \# \#} P<0.001$, ${ }^{\# \#} P<0.01$, and ${ }^{\#} P<0.05$.

TABLE 5: Effect of DZMP on the activities of SOD and T-AOC in serum $(n=10)$.

\begin{tabular}{lcc}
\hline Groups & SOD $(\mathrm{U} / \mathrm{mL})$ & T-AOC $(\mathrm{mg} / \mathrm{mL})$ \\
\hline BC & $156.25 \pm 3.98$ & $0.51 \pm 0.04$ \\
MC & $79.34 \pm 12.16^{* * *}$ & $0.32 \pm 0.03^{* * *}$ \\
PC & $150.90 \pm 10.85^{\# \# \#}$ & $0.48 \pm 0.06^{\# \# \#}$ \\
HD & $132.81 \pm 3.36^{\# \# \#}$ & $0.41 \pm 0.06^{\# \# \#}$ \\
MD & $119.05 \pm 4.28^{\# \# \#}$ & $0.37 \pm 0.08^{\#}$ \\
LD & $112.04 \pm 5.52^{\# \# \#}$ & $0.33 \pm 0.03$ \\
\hline
\end{tabular}

Compared with the normal group: ${ }^{* * *} P<0.001,{ }^{* *} P<0.01$, and ${ }^{*} P<0.05$. Compared with the model group: ${ }^{\# \# \#} P<0.001$, ${ }^{\# \#} P<0.01$, and ${ }^{\#} P<0.05$.

TABLE 6: Effects of DZMP on CAT and MDA activities in the liver tissues $(n=10)$.

\begin{tabular}{lcc}
\hline Groups & CAT (U/mgprot) & MDA (nmoL/mgprot) \\
\hline BC & $18.50 \pm 0.74$ & $0.95 \pm 0.08$ \\
MC & $12.01 \pm 0.90^{* * *}$ & $1.35 \pm 0.09^{* * *}$ \\
PC & $29.73 \pm 0.79^{\# \# \#}$ & $1.00 \pm 0.05^{\# \# \#}$ \\
HD & $22.81 \pm 1.00^{\# \# \#}$ & $0.99 \pm 0.05^{\# \# \#}$ \\
MD & $20.95 \pm 1.12^{\# \# \#}$ & $1.04 \pm 0.06^{\# \# \#}$ \\
LD & $19.00 \pm 0.96^{\# \# \#}$ & $1.21 \pm 0.09^{\# \# \#}$ \\
\hline
\end{tabular}

Compared with the normal group: ${ }^{* * *} P<0.001$, ${ }^{* *} P<0.01$, and ${ }^{*} P<0.05$. Compared with the model group: ${ }^{\# \# \#} P<0.001,{ }^{\# \#} P<0.01$, and ${ }^{\#} P<0.05$.

2.8.5. MS Analysis. After the liquid phase separation, the peptides were ionized by a nanoESI ion source and then transferred to Q Exactive HF-X (Thermo Fisher Scientific, San Jose, CA) in tandem mass spectrometry for detection in a data-dependent acquisition (DDA) mode. The main parameter was set as follows: the ion source voltage was set to $1.9 \mathrm{kV}$, the scanning range of primary mass spectrometry was $350 \sim 1500 \mathrm{~m} / z$ with a resolution of 60,000 , and the initial $\mathrm{m} / \mathrm{z}$ of the secondary mass spectrometry was $100 \mathrm{~m} / \mathrm{z}$ with a resolution of 30,000 . Under the condition of charge from $2^{+}$to $6^{+}$, the first 20 parent ions with the highest ion peak, the strength of which were over 20,000 , were classified as the parent ions of the secondary fragmentation. Ion fragmentation mode was set in HCD, and fragment ions were detected in Orbitrap. In addition, the dynamic exclusion time was set to $30 \mathrm{~s}$ and the automatic gain control targets (AGCs) of primary mass spectrometry and secondary mass spectrometry were to 3E6 and 1E5, respectively.

The work from extraction to analysis was done by the BGI Group in Shenzhen.

2.9. Western Blotting. About $30 \mathrm{mg}$ of mouse liver was taken, fully ground in RIPA lysate, and centrifuged at $4^{\circ} \mathrm{C}$ and $12000 \mathrm{rpm} / \mathrm{min}$ for $10 \mathrm{~min}$. The supernatant was taken and the protein concentration was determined by BCA protein quantitative assay kit (Solarbio). Both Fc $\gamma$ RIII protein and PKC- $\alpha$ were analyzed by this method.

2.10. SCFAs Were Determined by HPLC. The amount of $0.3 \mathrm{~g}$ of the contents of cecum was dissolved into $1 \mathrm{~mL}$ deionized water, $5 \mathrm{~mL}$ ether was added, and the aqueous phase at the lower layer was discarded for extraction. The solution was reextracted with $500 \mathrm{~L}, 1 \mathrm{M} \mathrm{NaOH}$, followed by filtration through a $0.22 \mathrm{~m}$ filter after adding $100 \mathrm{~L} \mathrm{HCl}$. The concentration of SCFAs in cecal contents including acetic acid, propionic acid, and butyric acid was analyzed by a Shimazu LC20A HPLC with a C18 column according to previous research [30].

2.11. 16S rRNA Sequencing. The combined cecal content (200 mg) was evaluated by Qubit ${ }^{\circledR}$ dsDNA BR Assay Kit for DNA extraction. $30 \mathrm{ng}$ of qualified genomic DNA samples were amplified in V3-V4 regions, and HiSeq platform was selected for sequencing. The DNA extraction and sequencing were carried out by the BGI Group in Shenzhen.

2.12. Bioinformatics and Statistical Analysis. The protein IBT was quantified, and the identified protein and peptide segments were obtained by $1 \%$ false discovery rate (FDR) filtration (PSM level:FDR $\leq 0.01$ ). Euclidean distance and a hierarchical cluster method were used to cluster the differential proteins. The obtained differential proteins were 


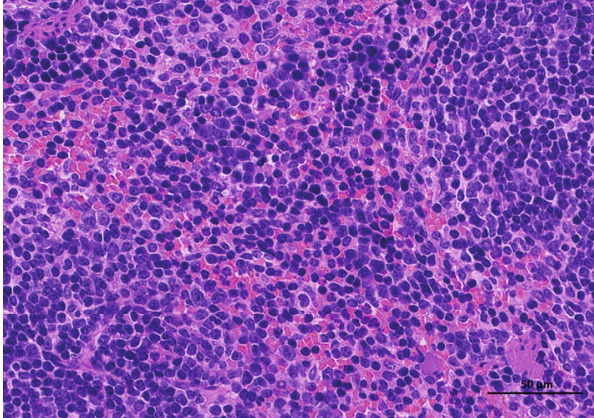

(a) (BC group)

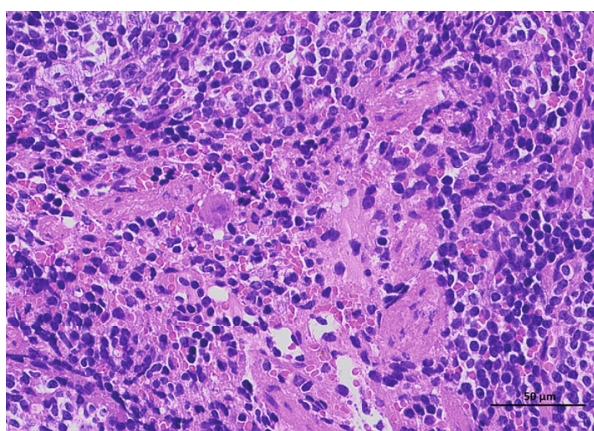

(c) (PC group)

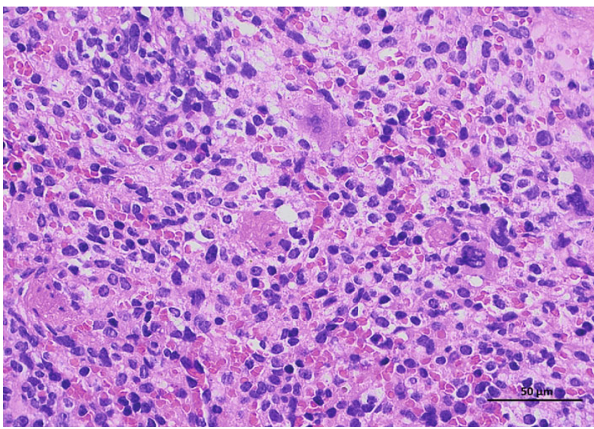

(e) (MD group)

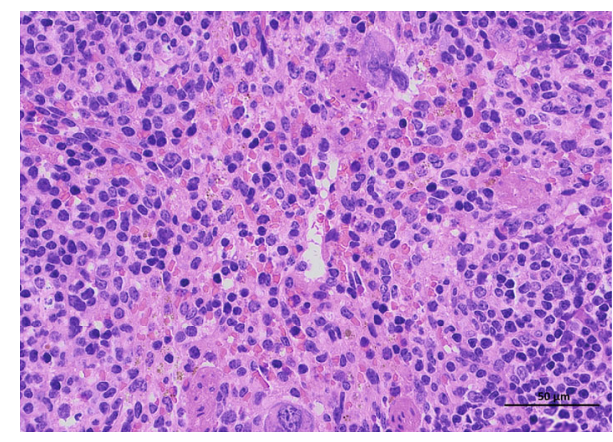

(b) (MC group)

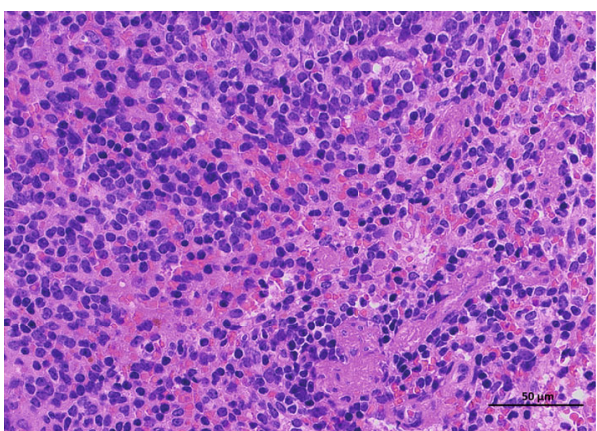

(d) (HD group)

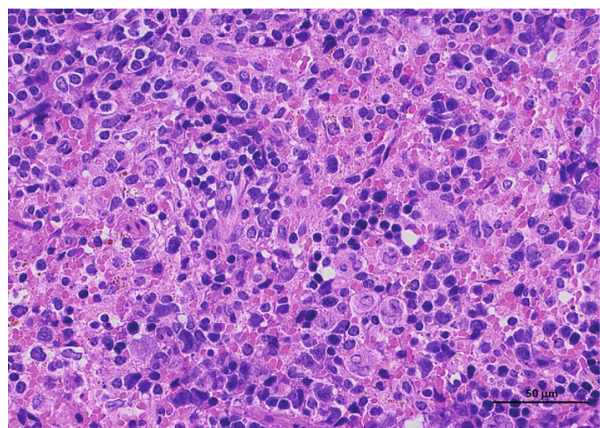

(f) (LD group)

FIGURE 1: Histopathological section of the spleen (400x).

compared with the NR database, and GO functional annotations were obtained. Besides, the KEGG Pathway Database was used to analyze metabolic abnormalities.

Reads obtained from sequencing cecal contents were spliced in pairs by FLASH software to get tags. After quality screening, OTU clustering was conducted with $97 \%$ similarity, and reference database Greengene was used for comparison. The data was analyzed taxonomically by the Ribosomal Database Program (RDP) classifier. Principal component analysis (PCA) was also carried out on the basis of a similarity coefficient matrix, and beta diversity comparison was performed by QIIME (V1.80).

All results were presented as the means \pm standard error. Statistical significance was performed by SPSS 19.0 software with a single-factor analysis of variance (one-way ANOVA).

\section{Results}

3.1. Effects of DZMP on Thymus Index and Spleen Index. In Table 2, the spleen index and thymus index in the MC group were significantly lower than those in the BC group $(P<0.001)$ indicating that the model was successful. Compared with the MC group, the thymus and spleen indexes in the HD group were significantly increased $(P<0.01)$. The thymus index of the MD group and the LD group was higher than that of the MC group, despite at a nonsignificant level.

3.2. Effect of DZMP on Cytokine Content in Mice. In Table 3, the levels of IL-2, IL-4, IL-6, and TNF- $\alpha$ in the MC group were significantly lower than those in the BC group $(P<0.01)$, indicating that CTX could inhibit immune activity. The decreased levels of IL-2, IL-4, IL-6, and TNF- $\alpha$ in mice induced by CTX were improved after the gavage of different doses of DZMP; the HD group especially had the best effect, which was similar to that of the PC group. The results showed that DZMP could improve immunity from the CTXinduced immunosuppressive situation by regulating the level of cytokines. 


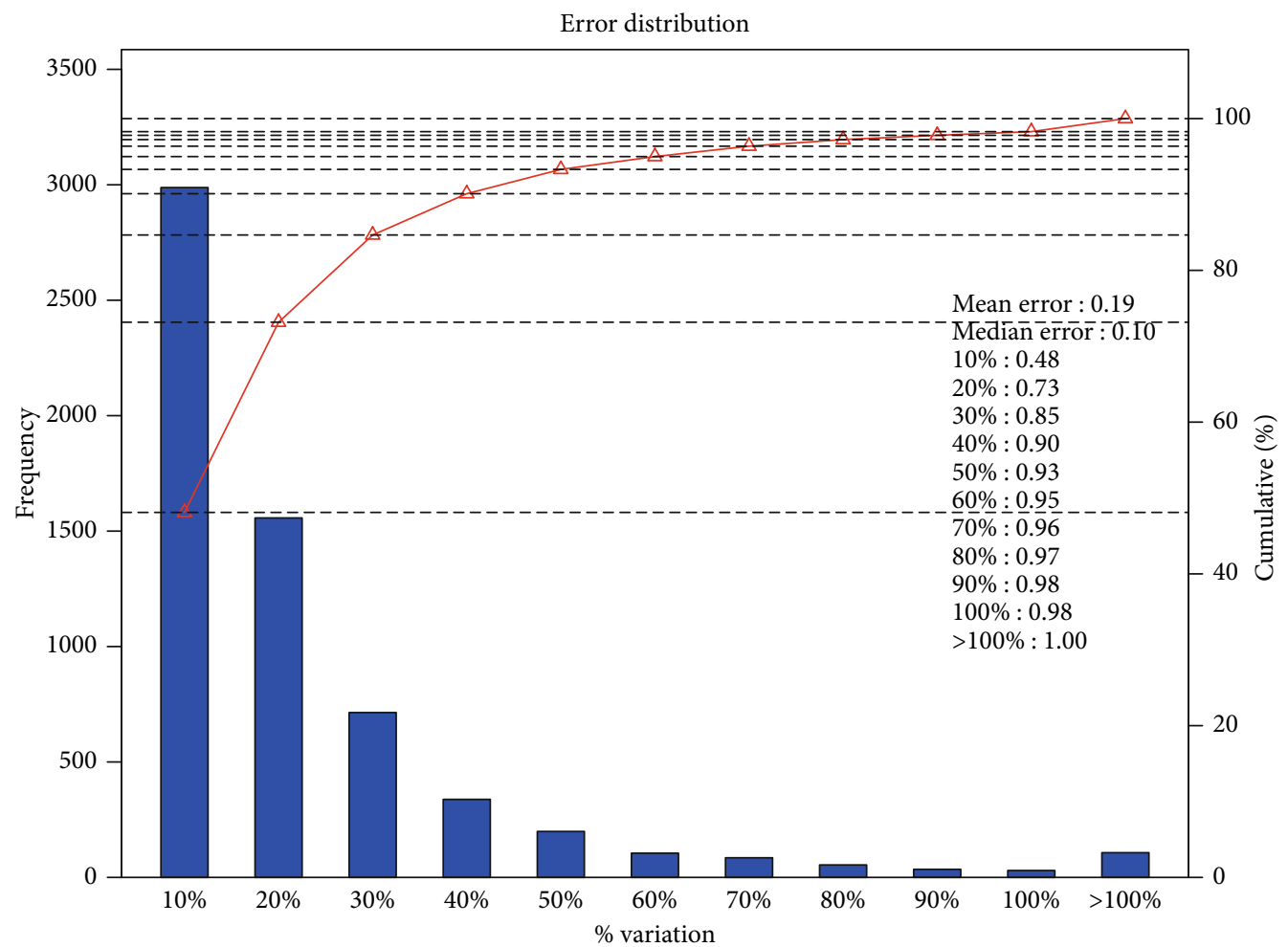

(a)

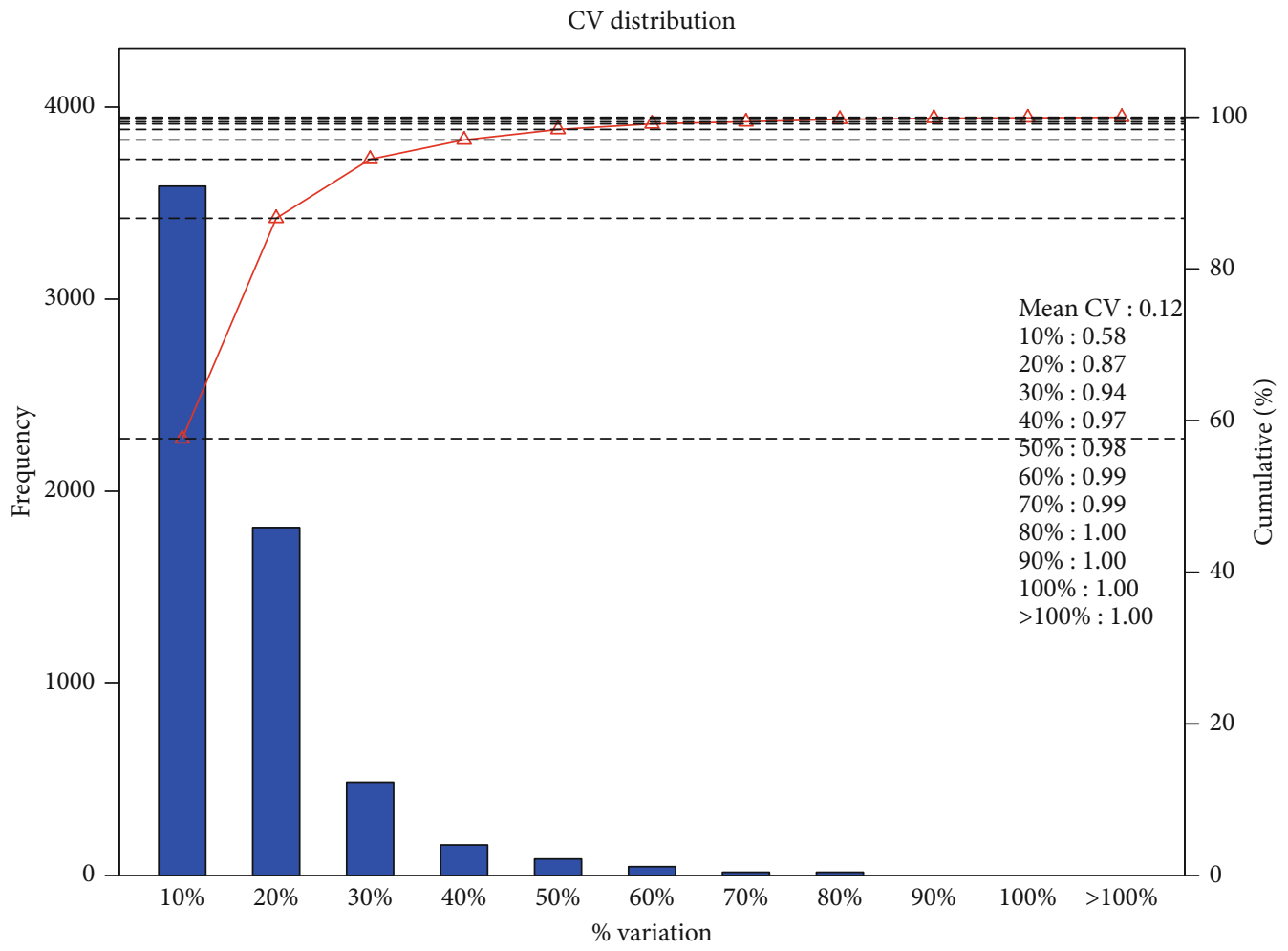

(b)

FIGURE 2: Intragroup and intergroup repeat experiment distribution.

3.3. Effect of DZMP on the Activity of ACP and LDH in Mice. In Table 4, the serum activities of ACP and LDH in the MC group were lower than those in the $\mathrm{BC}$ group. After corre- sponding treatments in the other groups, the activities of ACP in all the other 4 groups were significantly increased $(P<0.01)$ while $\mathrm{LDH}$ activities only in the $\mathrm{HD}$ and $\mathrm{MD}$ 

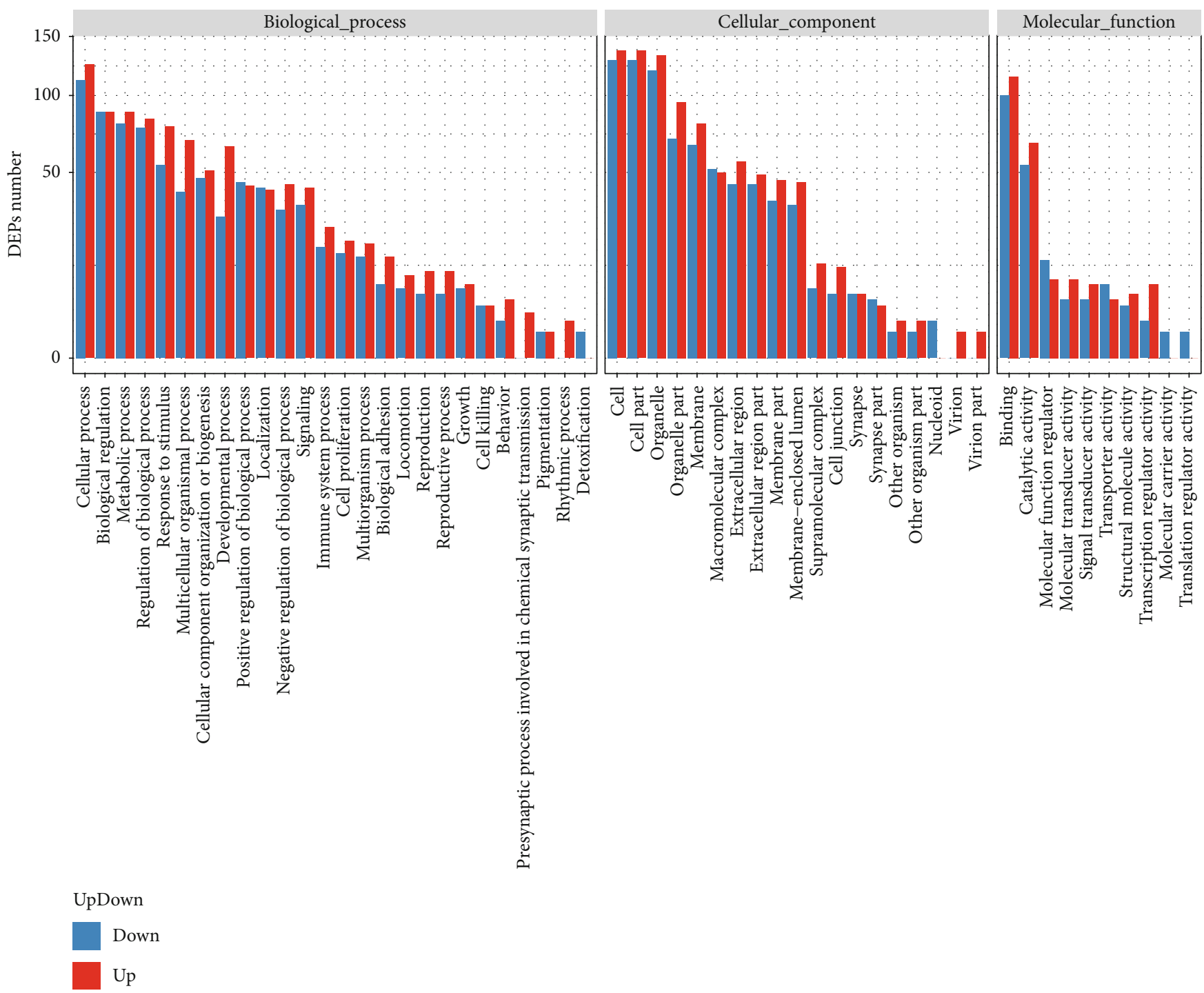

FIGURE 3: Statistical diagram of downregulated GO functional classification of differential proteins in the MC group and the HD group.

groups were significantly increased $(P<0.05)$. Among them, the activities of $\mathrm{LDH}$ in the $\mathrm{HD}$ and $\mathrm{MD}$ groups as well as ACP in the HD group were higher than that in the PC group. The results indicated that DZMP could significantly enhance the activity of ACP and $\mathrm{LDH}$ in mice.

3.4. Effect of DZMP on Antioxidant Capacity of Mice. In Table 5, SOD and T-AOC in the MC group were significantly lower than those in the $\mathrm{BC}$ group $(P<0.001)$, indicating that the antioxidant capacity was successfully inhibited by CTX. Both SOD and T-AOC activities showed a close level among the PC, HD, and BC groups. Therefore, compared with the MC group, administration with highdose DZMP could almost recover the activities of SOD and T-AOC $(P<0.001)$. In addition, SOD activity in the MD and LD groups was also increased significantly $(P<0.001)$.

In Table 6 , compared with the $\mathrm{BC}$ group, CAT activity in the MC group was significantly decreased $(P<0.001)$ and MDA activity was significantly increased $(P<0.001)$, indicating that the model was established. Compared with the
MC group, the CAT activity of the PC group fed with Lentinula edodes polysaccharide tablets was the highest, followed by the $\mathrm{HD}, \mathrm{MD}$, and LD groups, which were all significantly higher than that of the MC group $(P<0.001)$. Meanwhile, the MDA activities of these groups were significantly lower than that of the MC group $(P<0.001)$ and the MDA content of the HD group was as low as the PC group. Thus, DZMP has antioxidant ability.

3.5. Effect of DZMP on Pathological Changes of Immune Organs in Mice. In Figure 1, spleen tissues of mice in the BC group were in normal shape, with no abnormal cell arrangement, while there had been disordered cell arrangement and a reduced number in the MC group. Compared with the MC group, administration of DZMP in the HD, $\mathrm{MD}$, and LD groups increased the cell density and the cells were closely and orderly arranged. This result indicated that the DZMP could alleviate the injury of immune organs caused by CTX. 


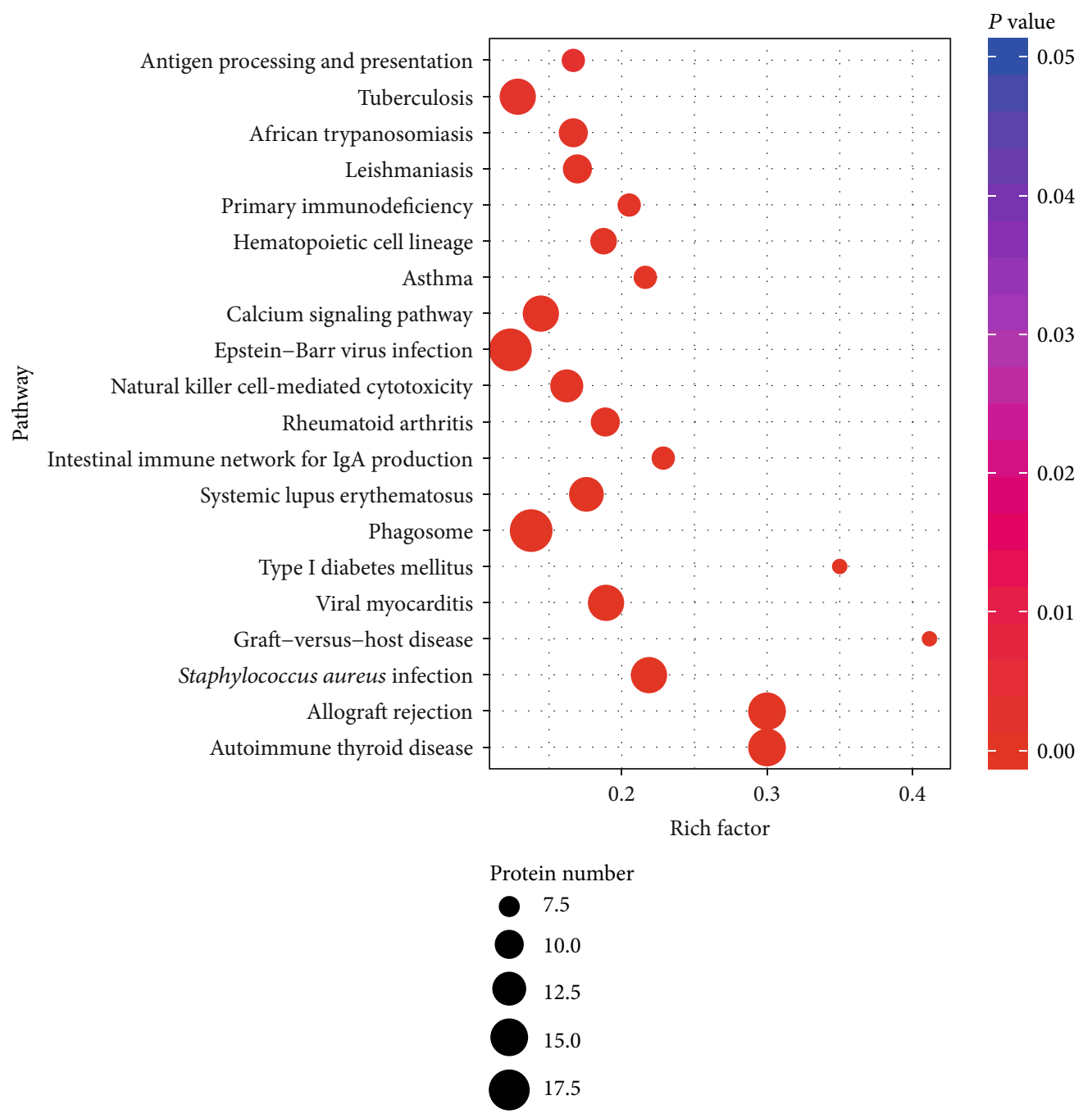

(a)

Figure 4: Continued. 


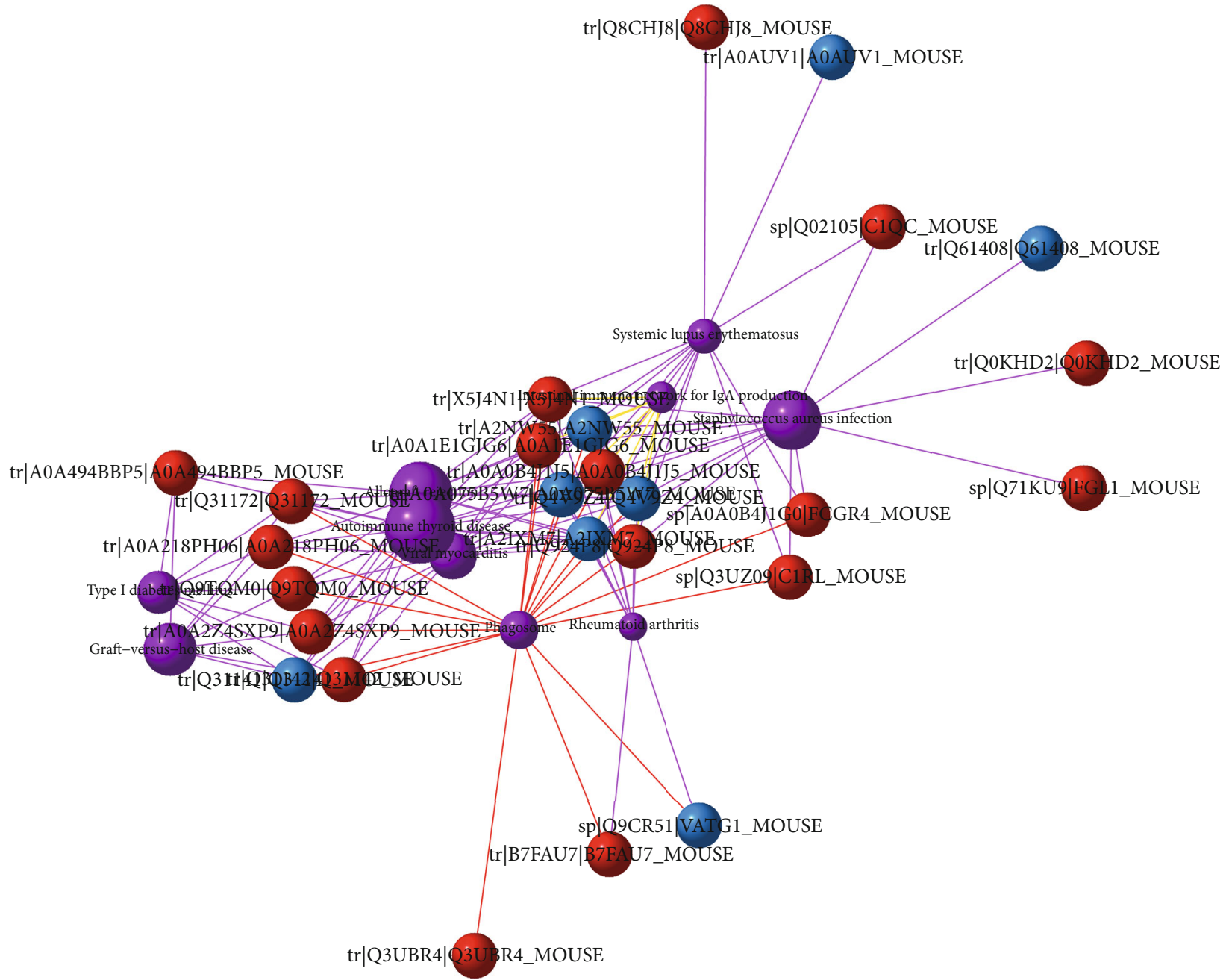

(b)

Figure 4: Pathways of significant enrichment (a) and the relationship network diagram (b) of the HD and MC groups. The purple balls are the top 10 enriched pathways, and the relative area of each ball is the richness of the corresponding pathway. The red balls and blue balls are the upregulation and downregulation differential proteins, respectively.

3.6. Enrichment Analysis of Differential Protein Function. There were a total of 9 samples with functional enrichment of differential proteins, which symbiotically formed 718,399 secondary spectrograms. A total of 36,679 peptides and 6229 proteins were identified under the "1\% FDR" filtration standard. In Figure 2, the mean error value in the group was 0.19 and the mean $\mathrm{CV}$ value between the groups was 0.12 . Moreover, the protein with a $\mathrm{CV}$ value less than $20 \%$ accounted for $87 \%$, indicating that the biological repeatability between the sample groups was good. The differential proteins among different groups were screened by differential multiples and significance. Based on the functional enrichment analysis results of differential protein, it could indicate that $\mathrm{Fc} \gamma \mathrm{RIII}$ and PKC- $\alpha$ mediate the effect among multiples.

Cluster analysis was carried out for GO entries with significant enrichment. In Figure 3, most of the differentially expressed proteins in the MC group and the HD group were in the biological process, cell component, and molecular function, and the most significant differences were cellular process, cell component, and binding, respectively.

The differentially expressed proteins in the $\mathrm{HD}$ and $\mathrm{MC}$ groups were mainly involved in 20 KEGG pathways, and about 10-45 differentially expressed proteins were involved in each pathway (Figure 4(a)). Figure 4(b) shows that protein upregulation was the majority in the top 10 enriched pathways. RichFactor is a parameter calculated by dividing the number of annotated differentially expressed proteins into all proteins identified in this pathway, and the higher the RichFactor is, the greater the proportion of differential proteins in the pathway is. In Figure 4, the four pathways, graft versus host disease, type I diabetes mellitus, allograft rejection, and autoimmune thyroid disease, owned the highest differential protein proportion, while Epstein-Barr virus infection, phagosome, and tuberculosis were the pathways with the highest number of different proteins. To analyze the interaction among differential proteins, they were imported into STRING, a protein interaction database, and 


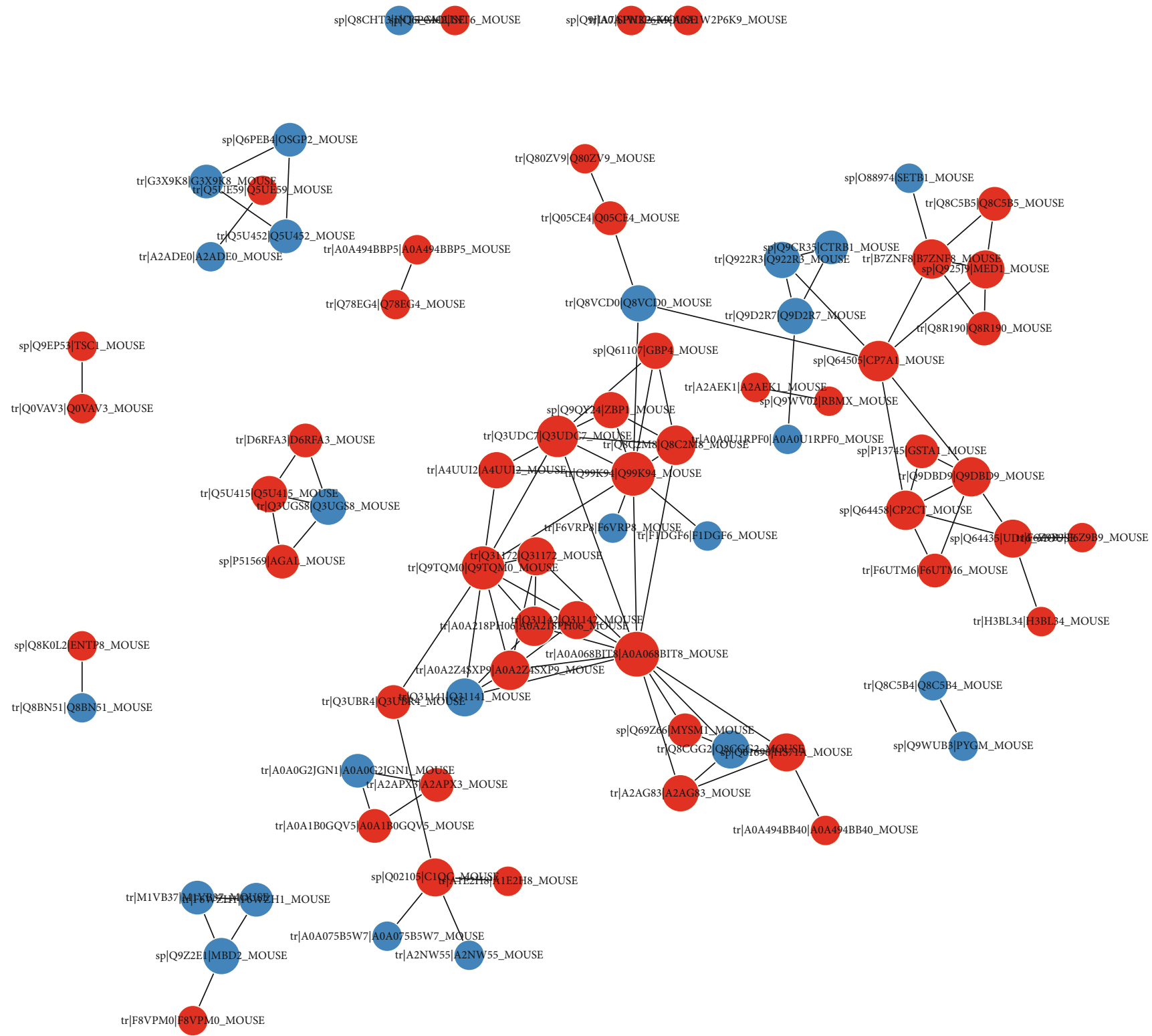

FIGURE 5: Network diagram of the differential protein interaction between the HD and MC groups.

compared. The protein interactions ranking at the top 100 in trustworthiness were plotted in Figure 5.

The proteins could participate in the various life activities of the cell only when they are transported to the right places after they are synthesized in the ribosome. WoLF PSORT and PSORTb were used to predict the subcellular location of proteins for eukaryotes and prokaryotes, respectively. In Figure 6, the subcellular localization results of $\mathrm{HD}$ and $\mathrm{MC}$ differential proteins reveal that the differential proteins were more widely distributed in the nucleus (nucl), cell fluid (cyto), extracellular fluid (extr), mitochondria (mito), and plasma membrane (plas).

3.7. Protein Validation. The results of Fc $\gamma$ RIII and PKC- $\alpha$ protein in Figure 7 show that the protein expression in the $\mathrm{MC}$ group was significantly lower than that in the BC group. Compared with the MC group, the HD group significantly increased protein expression and it was consistent with the results of proteomics.

3.8. Evaluation of Microbial $16 S$ rRNA Gene Sequencing. After gene sequencing and data quality filtering, a total of 2,301,428 high-quality readings were obtained, and about 1143,329 tags were spliced together. These tags were clustered into OTUs with $97 \%$ similarity, and a total of 756 OTUs were obtained. In Figure 8(a), the transverse bend line was wider, and the line eventually tends to be flat, indicating that the species composition in the tested samples was abundant and uniform. In Figure 8(b), the rising trend at the top of the OTU accumulation curve was gradually stable, indicating that the amount of sampling was sufficient to represent the community structure of the sample community in this experiment, and following data analysis was feasible. 


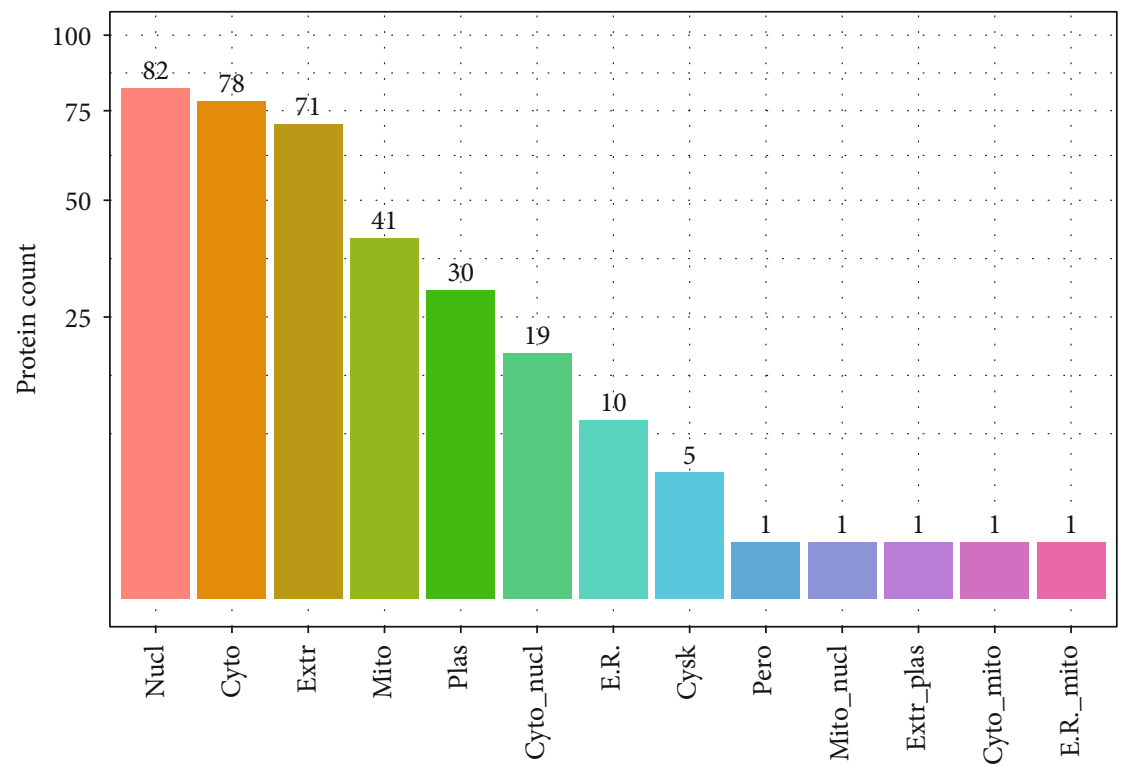

Figure 6: Histogram of subcellular localization of HD and MC differential proteins. nucl: nucleus; cyto: cytosol; extr: extracellular; mito: mitochondria; plas: plasma membrane; E.R.: endoplasmic reticulum; cysk: cytoskeleton; pero: peroxisome.
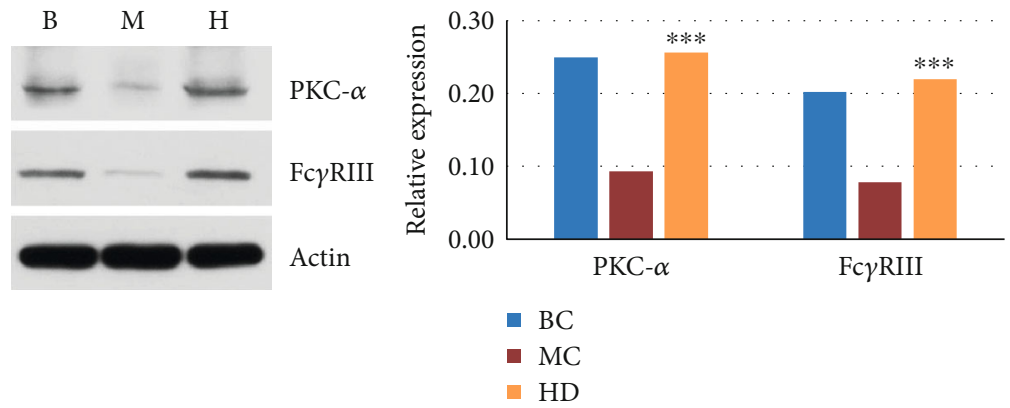

FIgURE 7: Fc $\gamma$ RIII protein and PKC- $\alpha$ are expressed in different groups of the liver.

The microbial communities in different environments have certain similarity and specificity in species distribution. According to the OTU abundance information, Venn diagram analysis was performed to compare the commonness or uniqueness of OTUs between different groups. In Figure 9, each group had its special community representation. Among them, the BC group and the HD group had more specific OTUs than that of the MC group.

The analysis results of alpha diversity and beta diversity are shown in Figures 10 and 11, respectively. In Figure 10, the observed species index, Chaol index, ACE index, and Shannon's index of the BC, LD, and MD groups were all higher than that of the $\mathrm{HD}, \mathrm{MC}$, and $\mathrm{PC}$ groups. It indicated that species richness was lower in the $\mathrm{HD}, \mathrm{MC}$, and $\mathrm{PC}$ groups. Good's coverage value of each group was higher than $99 \%$, indicating that the sample library had a high coverage rate and the sequencing results were reliable and feasible. The similarity or difference of the composition of the sample flora is presented by principal component analysis in Figure 11(a). The results showed that the first principal component accounting for $47.35 \%$ was contributed mainly by the
HD group. The results of hierarchical clustering (Figure 11(b)) showed that the microbial communities of each treatment group were close to each other on the whole, while the MC group was far away from the HD group.

In order to better identify the community composition of each sample, the taxonomic analysis of the microflora information was carried out. In Figure 12, Firmicutes and Bacteroidetes were the two dominant bacteria groups in the samples, accounting for about $85 \%$ $95 \%$ of all bacteria, followed by Proteobacteria. Observation showed that the relative abundance of Firmicutes and Bacteroidetes in the BC group $(72.09 \%, 20.77 \%)$ was close to that of the corresponding bacteria species in the MC group (74.36\%, 20.71\%), indicating that the intra-abdominal injection of CTX had little impact on the two dominant bacteria groups. In the HD group, the relative abundance of Firmicutes decreased obviously (50.78\%), while that of Bacteroidetes and Proteobacteria increased relatively $(35.17 \%, 6.86 \%)$, compared with the BC group.

The species information of all samples detected at the genus level is plotted as a cluster heat map. In Figure 13, 


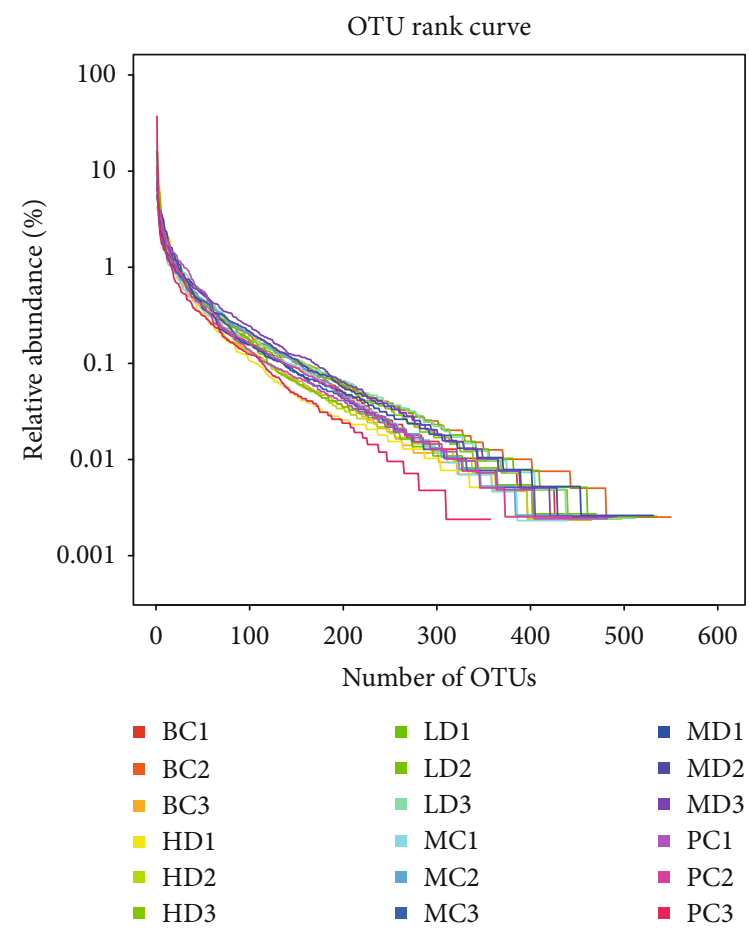

(a)

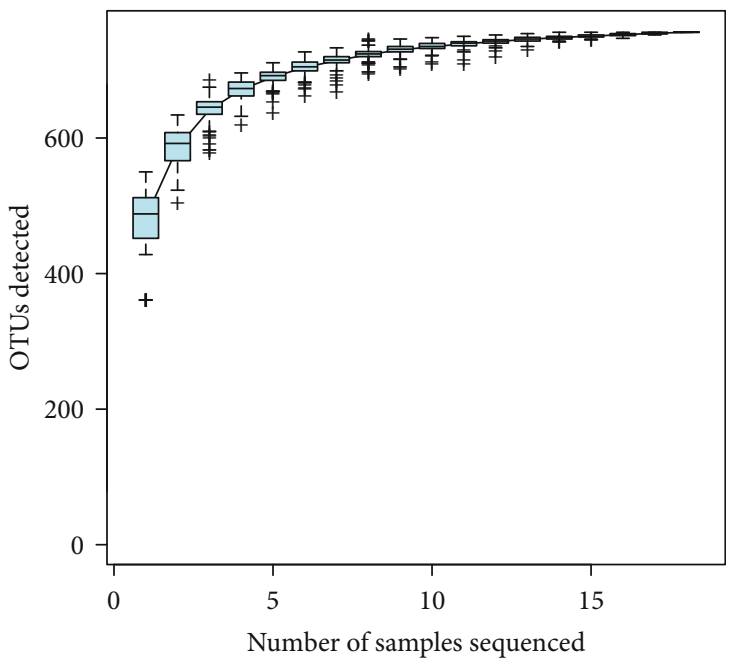

FIgURE 8: OTU rank curve (a) and OTU cumulative curve (b).

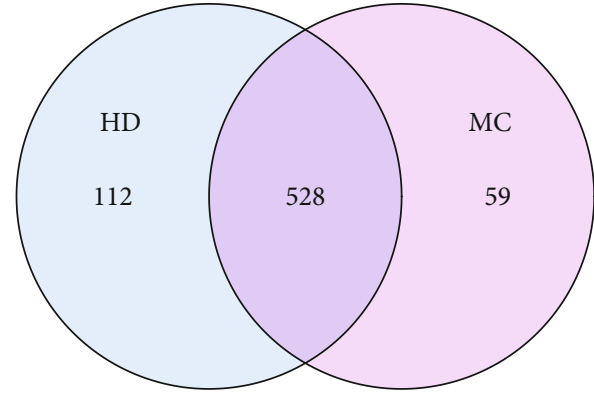

(a)

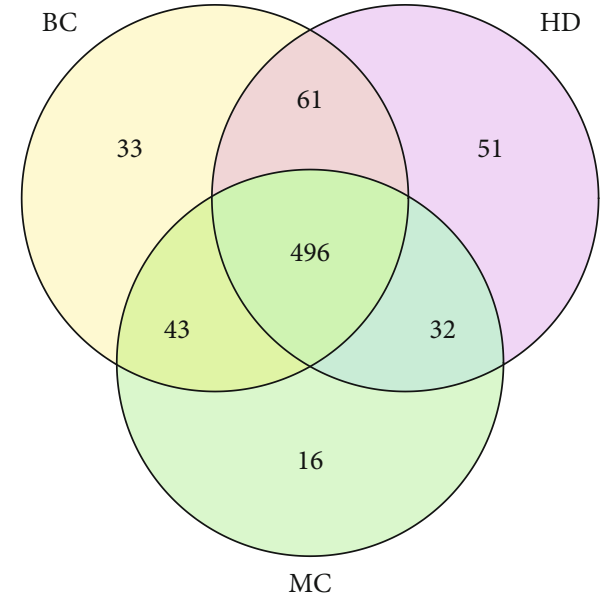

(b)

FIGURE 9: OTU Venn figure: comparison of the species similarity or specificity between groups.

the two genera with the highest relative abundance were Oscillospira and Prevotella, followed by Ruminococcus and Bacteroidetes. The relative abundance of Proteobacteria in the HD group was higher than that in $\mathrm{BC}$ group. At the same time, the relative abundance of Bacteroides, Paraprevotella, Akkermansia, Roseburia, CF231, Helicobacter, Sutterella, and Coprobacillus in the HD group were much higher than that in the MC group, while that of Ruminococcus and Oscillospira in the HD group were lower.

3.9. Effect of DZMP on SCFA Content. In Figure 14, compared with the $\mathrm{BC}$ group, the contents of acetic acid, propio- nic acid, and butyric acid in MC were significantly reduced, while the contents in the HD and PC groups were close to that in the $\mathrm{BC}$ group and significantly higher than that in the MC group. The results indicated that DZMP and Lentinula polysaccharide had a strong influence on the SCFA contents.

\section{Discussion}

Immune response is a series of immune reactions of the immune active cells in the immune system, including recognition of external stimuli as well as its activation, 

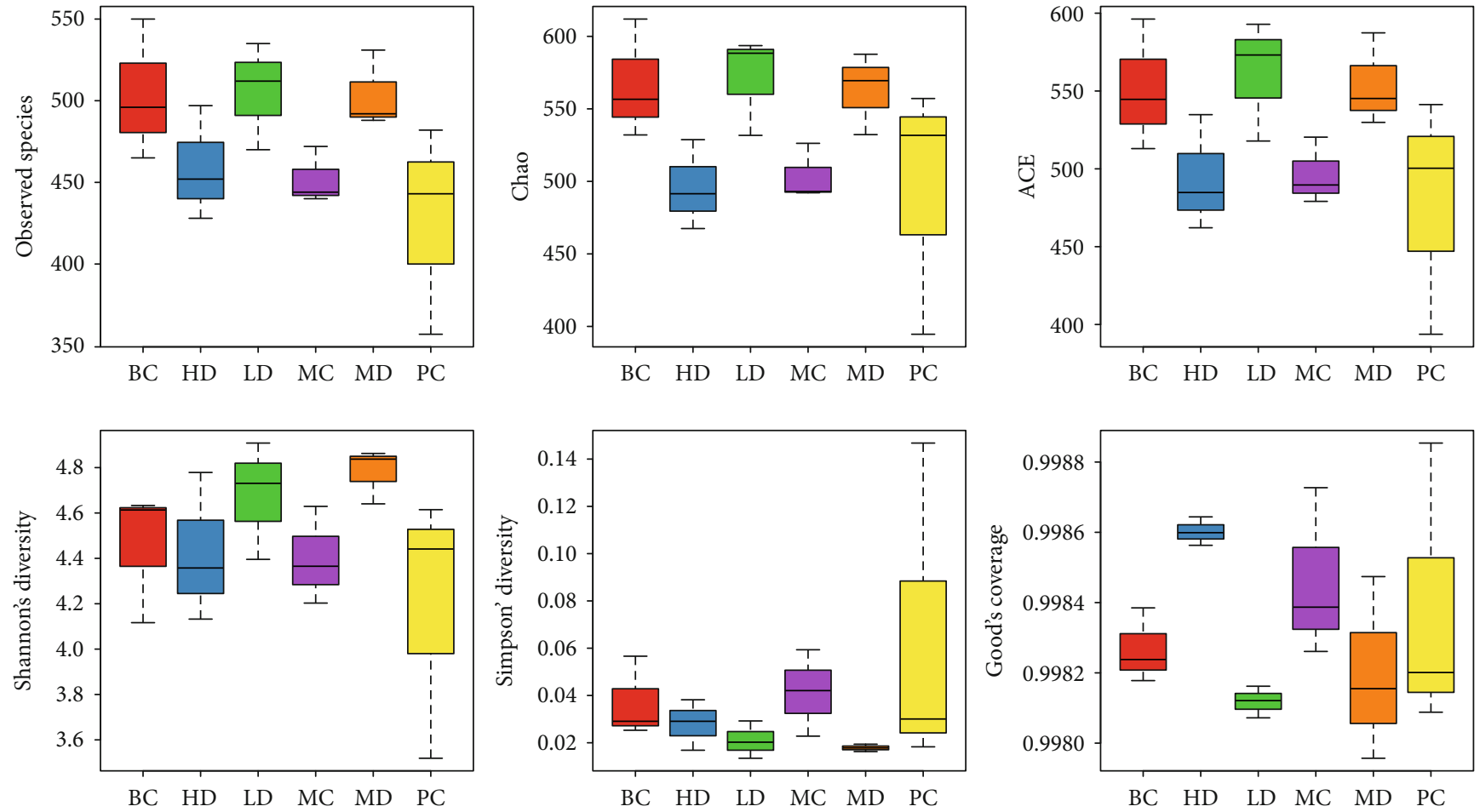

FIGURE 10: Alpha diversity box.

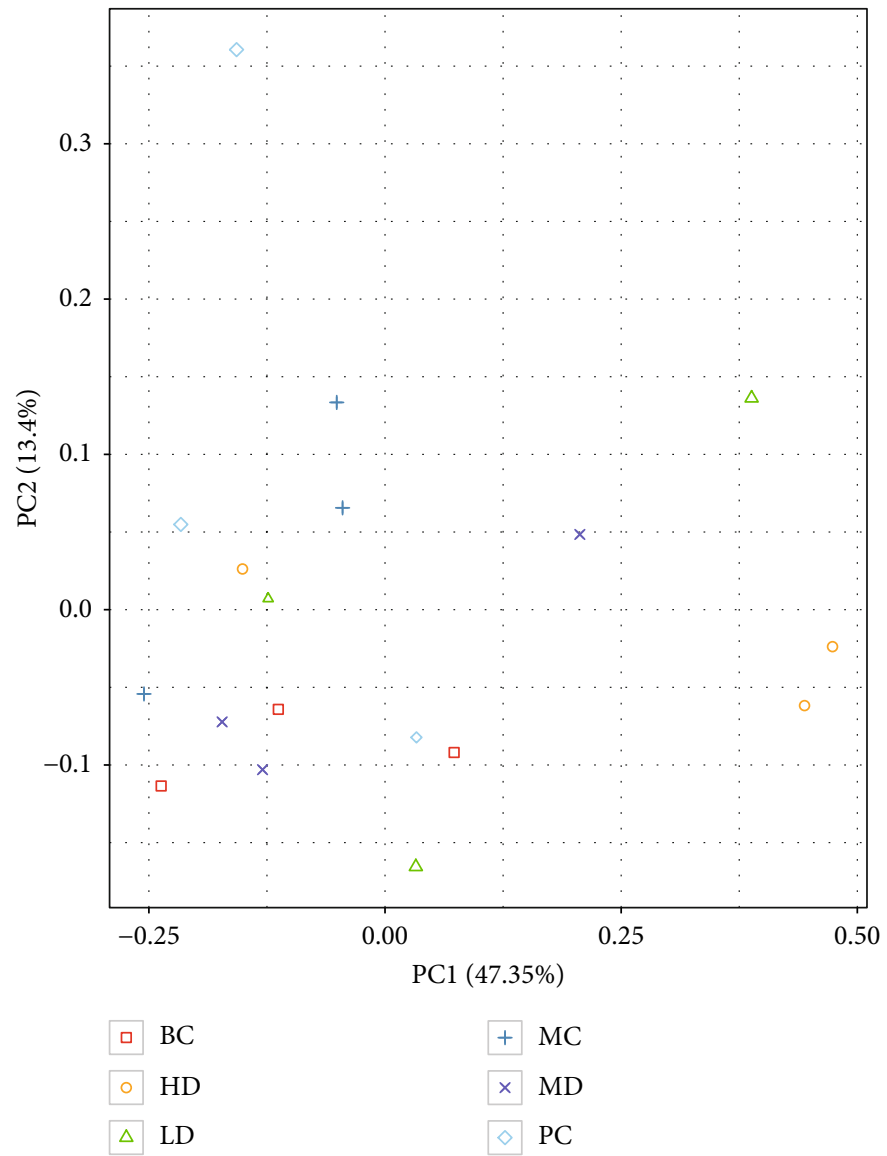

(a)

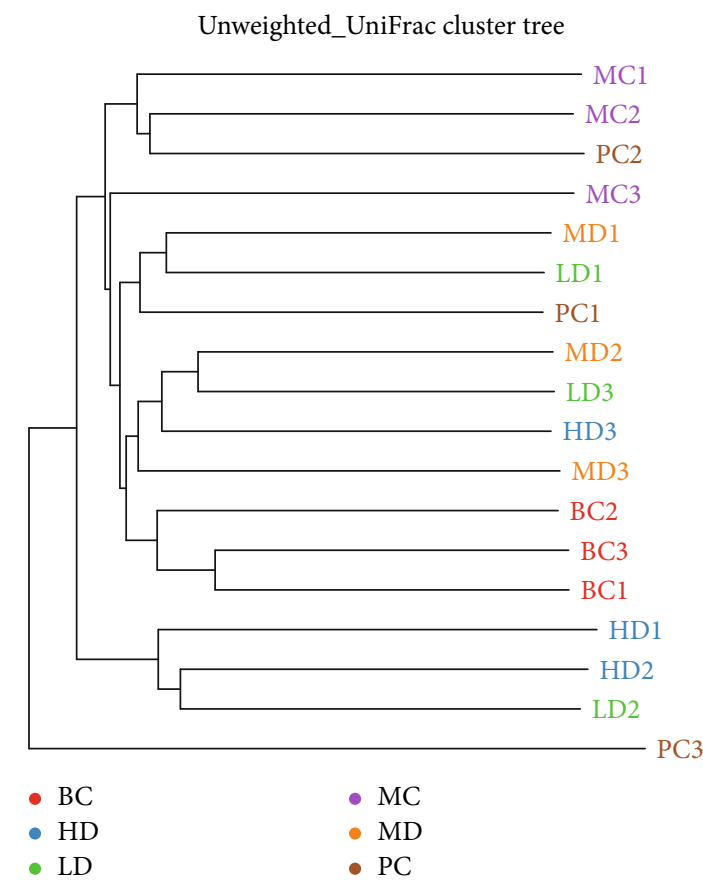

(b)

Figure 11: Beta diversity analysis. (a) Principal component analysis diagram. (b) Sample clustering tree (unweighted). 


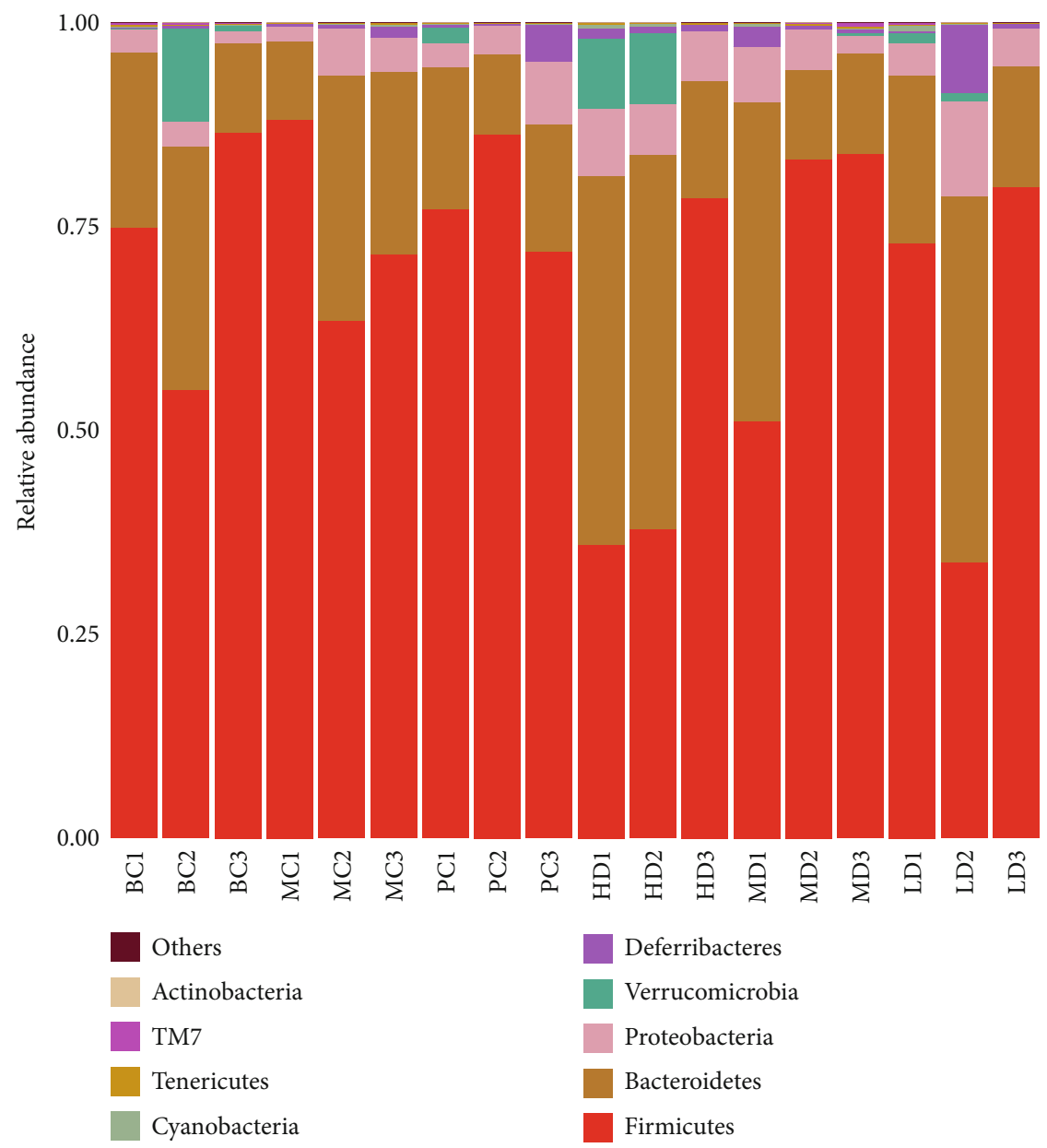

Figure 12: Relative abundance of major bacteria at phylum level.

proliferation, and differentiation [32-34]. Immune organs, including the thymus, spleen, and bone marrow, are important for the proliferation and growth of human immune cells. The changes of the thymus and spleen indexes can reflect intuitively the immune function of the body, and the decline of immune function usually accompanies with the shrinkage of immune organs [35]. Previous studies have shown that Citrus pericarp and Litchi pulp polysaccharides could significantly improve the thymus and spleen indexes in mice [36, 37]. In this experiment, the thymus and spleen indexes of mice were significantly decreased in the MC group, while they were significantly raised after the treatment of DZMP in the HD group, indicating that DZMP can alleviate CTX damage to the thymus and spleen and enhance the immune ability of the body.

Macrophages, an important type of immune cell, can participate in the immune response and protect the normal operation of the body by identifying antigens, killing/engulfing foreign pathogens, releasing cytokines, or secreting cytotoxic molecules after being activated [38]. The activity of ACP and LDH can directly reflect the activation of macrophages [39, 40]. In this study, ACP and LDH activities were significantly enhanced in the HD and MD groups compared with the MC groups. The results showed that DZMP could regulate the activities of
$\mathrm{LDH}$ and ACP in mice and activate macrophages to participate in immune response. Previous studies have shown that cytokines have multiple immune functions [41]. In this experiment, IL-2, IL-4, IL-6, and TNF- $\alpha$ in the MC group were significantly decreased, indicating that CTX had an immunosuppressive effect, which was consistent with the results of Tang et al. [42]. The Th1 and Th2 subgroups of mice can secrete IL-2 and IL-4, respectively, and both IL- 2 and IL-4 can promote the proliferation of T cells $[43,44]$. In addition, IL-4 can also promote the expression of $\mathrm{B}$ cells, enhance the antigen presentation ability of B cells, increase IgG1 and IgE levels, and make the responses of immune system to antigen stimulation $[45,46]$. Gong et al. found that Bletilla baicalensis polysaccharides could significantly enhance the levels of IL-2 and IL-4 in immunosuppressed mice [47] which is similar with the effect of DZMP in this paper. TNF- $\alpha$ and IL- 6 are the major cytokines in macrophages. TNF- $\alpha$, as a proinflammatory cytokine, can directly kill tumor cells [48], while IL-6 can promote the proliferation and differentiation of lymphocytes [49], and both of them play important roles in a variety of immune responses. The results of this experiment showed that DZMP could significantly increase the levels of IL-2, IL-4, IL-6, and TNF- $\alpha$ in serum of mice, thus playing an immunomodulation role. 


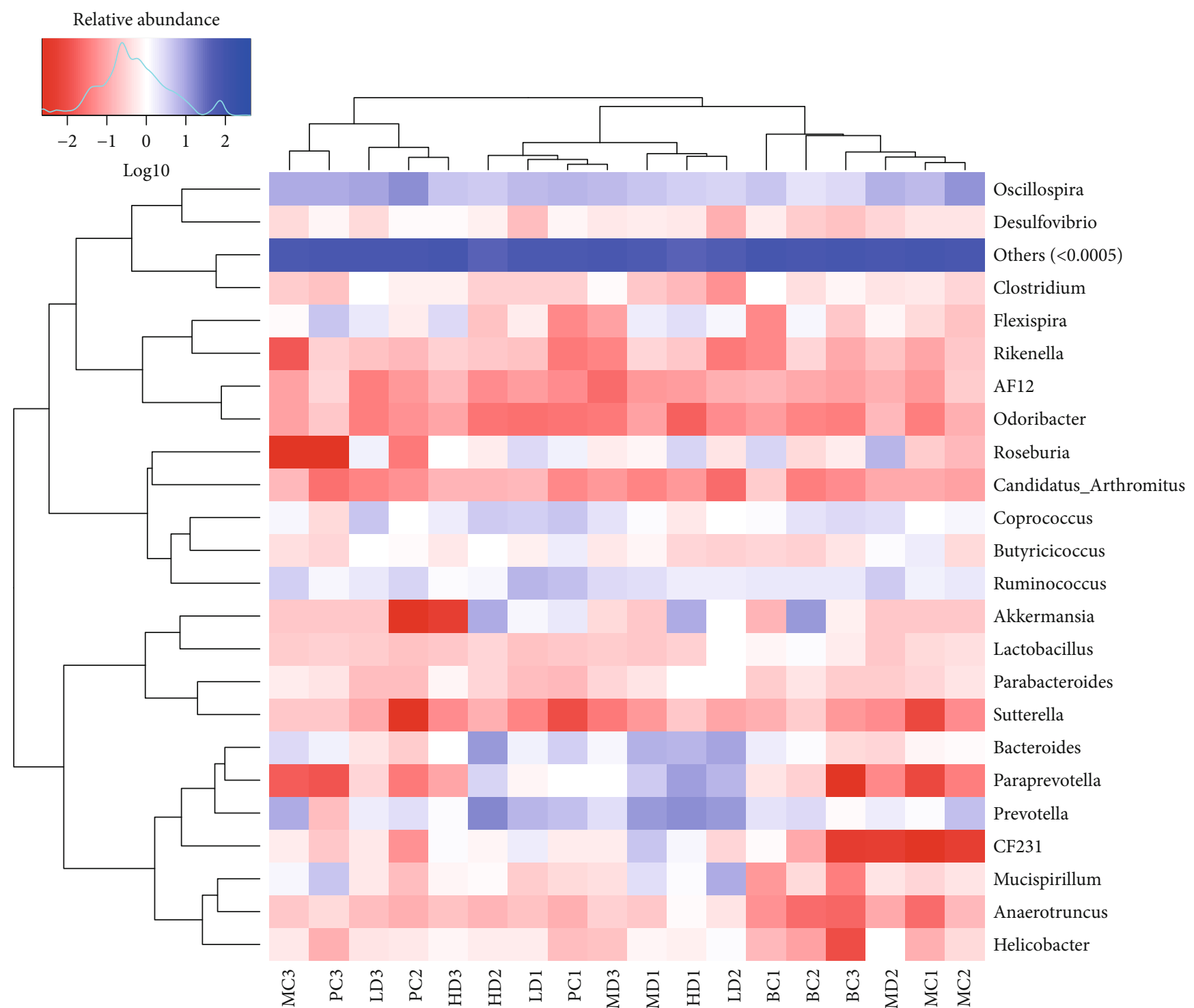

FIGURE 13: Relative abundance heat map of flora at genus level.

The liver is an important metabolic organ with a strong function of biotransformation [50]. The cytotoxicity of many chemotherapeutic drugs in the metabolic process of the body can easily cause organic damage to the liver as well as the activities of metabolic enzymes [51-53]. CTX is mainly converted into 4-hydroxycyclophosphamide and aldehyde phosphamide by CYP450 enzymes in the liver, and then distributed throughout the body. After that, CTX can enter target cells and alkylate DNA, generating strong cytotoxicity $[50,54]$. Clinically, polysaccharides are often used as adjuvant drugs together with chemotherapy drugs to reduce their toxicity, improve the body's immunity, and strengthen the recovery [55-57]. Polysaccharides usually have many pharmacological activities, like multitargets and wide effects $[22,58]$. For this reason, proteomics technology was used for the expression of proteins at the whole gene level, and IBT quantitative analysis for the key differential proteins, so as to provide analytical basis for studying specific drug action protein targets and their interactions. In this study, the differential proteins of untreated, immunosuppressed, and DZMP-treated mice were compared to find the protein targets.

The results showed that Fc $\gamma$ RIII and PKC- $\alpha$ exerted regulatory effects on multiple pathways. Fc $\gamma$ RIII consists of CD16a and CD16b, expressed by Fc $\gamma$ R NK cells, and some other immune cells [59]. Both CD16a and CD16b can bind to IgG, a monomer on target cells, which plays an important role in the clearance of immune complexes and the function of NK cells, respectively $[60,61]$. Both of the subtypes can rapidly undergo proteolysis when neutrophils and NK cells are subjected to various stimuli, and fall off from the surface of human white blood cells $[62,63]$. Studies have shown that CTX can enhance the phagocytic activity of macrophages to treat tumors by upregulation of Fc $\gamma$ RIII [64]. In this study, compared with the MC group, the expression of the Fc $\gamma$ RIII receptor in the treatment group was significantly upregulated, providing a theoretical basis for the function of DZMP in the treatment of cancer. Protein kinase C (PKC) is a type of multifunctional enzyme involved in the regulation of 


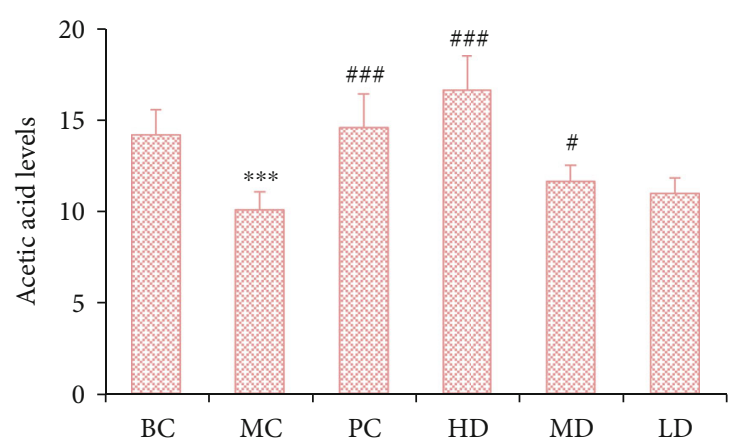

(a)

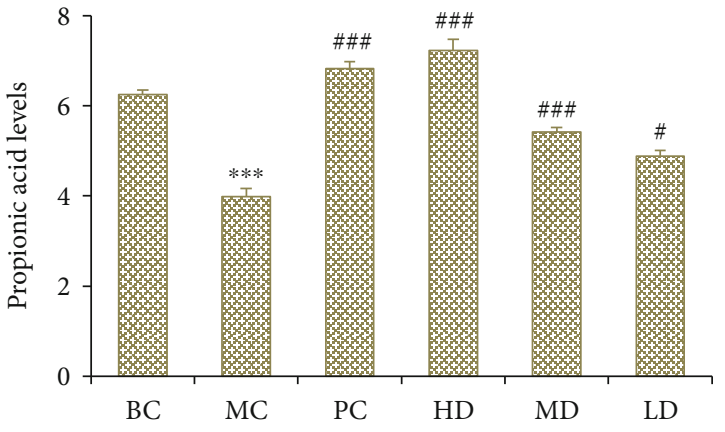

(b)

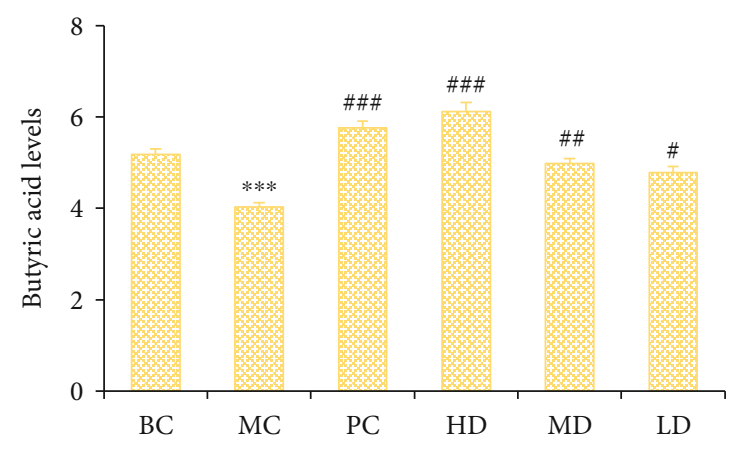

(c)

Figure 14: Acetic acid content in samples from each group (a), propionic acid content in each group (b), and butyric acid content in each group (c).

biochemical reactions by activating some enzymes in the cytoplasm. Meanwhile, it also acts on transcription factors in the nucleus and participates in the regulation of gene expression. Das et al. evidenced that PKC participated in the host protective immune response through the TLR2/PKC signal crosshair by the pretreatment of a TLR2 agonist, an Arabinosylated lipoarabinomannan (Ara-LAM), which could significantly increase the expression of conventional PKC in infected macrophages [65]. Mohammd et al. have shown that the extract of PKC has a probiotic and immunomodulatory effect on rats and enhances the antioxidant capacity of the rats' liver [66]. There are three isoforms, PKC- $\alpha$, PKC- $\beta$, and PKC- $\theta$, contributing to the nature of lymphocyte-specific effector responses in vivo [67]. Take PKC- $\alpha$ for example, acid phosphatase can activate its immune-stimulating activity by phosphorylating it [68]. In this study, the expression of PKC- $\alpha$ was increased in the HD group of DZMP. The above results indicated that DZMP might play a role in the immune regulation by upregulating the expression of Fc $\gamma$ RIII and PKC- $\alpha$ to regulate the drug metabolism-related pathways such as autoimmune disease, Staphylococcus aureus infection, and the NF- $\kappa \mathrm{B}$ signaling pathway.

The coexisting flora of the human gastrointestinal tract constitutes a relatively stable microecosystem. Rehman et al. proposed that the change of intestinal flora species number was related to the abnormal immune function [69]. Many previous studies also showed that probiotics combined with drugs could better treat gastritis, inflammatory bowel disease, allergic asthma, and other diseases in children, and enhance the immune function of the body [70]. Natural plant polysaccharides are one type of probiotics, which has been proven to regulate the physiological and immune functions of the body as well as improve the structure and composition of flora, and maintain the balance of intestinal microorganisms [14, 67-74]. The results of this study showed that the number of specific OTUs in the HD group was significantly higher than that in the MC group and its alpha diversity index is lower than that of the $\mathrm{BC}$ group, which revealed the regulation effect of DZMP on the dominant bacteria in the HD group.

In order to more accurately determine the changes in the composition of the intestinal microflora, the related assessments were carried out at different taxonomic levels. The research results show that Firmicutes and Bacteroidetes are two dominant bacteria, which promote polysaccharide metabolism through carbohydrate enzymes and enable the host to absorb and store energy [75, 76]. Turnbaugh et al. showed that the relative abundance of Firmicutes to Bacteroidetes in the intestinal flora of obese mice increased while that of Bacteroidetes decreased [77]. In our study, a high dose of DZMP can significantly reduce the relative abundance of Firmicutes and increase the relative abundance of Bacteroidetes, playing a beneficial regulatory role in the intestinal flora.

Plant polysaccharides also have beneficial effects on microbial fermentation of carbohydrates, such as shortchain fatty acids (SCFAs), which regulate body health [78, 79]. During the digestion of plant fibers, a particular genus of bacteria (Roseburia) in the gut can produce butyrate, which has been proven to be the main source of metabolic 
energy of large intestine cells, helping to maintain normal metabolism of large intestine cells, control intestinal inflammation, and support genomic stability $[80,81]$. Propionate, mainly produced by Bacteroides, a symbiotic bacterium in the human intestinal tract, can reduce the degradation of fat, the level of serum cholesterol, and the carcinogenic effect of other tissues [81, 82]. Prevotella and Coprococcus can degrade carbohydrates and polysaccharides to protect intestinal health [83-85]. Prevotella is also involved in the synthesis of multivitamins [86]. Akkermansia is a beneficial bacterium, which can reduce the risk of obesity, diabetes, inflammation, and other diseases, and maintain intestinal health [87-89]. In this paper, compared with the MC group, the relative abundance of Bacteroides, Prevotella, Coprococcus, and Akkermansia as well as the content of SCFAs in the HD group were significantly increased, which were consistent with the results of these mentioned study. Besides, Ruminococcus which was known to produce the acetic acid and formic acid and upregulate the barrier function of host intestinal epithelial cells was downregulated after the treatment of DZMP in this paper $[90,91]$. Similarly, the relative abundance of Oscillospira, which was directly proportional to health [92, 93], increased in the MC group (consistent with the study of Tang et al. [42]) and decreased after the treatment of DZMP in the $\mathrm{HD}$ group (slightly higher than that in the BC group). All these above results showed the balance effect of DZMP on these intestinal florae in mouse intestinal tract.

\section{Conclusion}

DZMP can protect the immune organs of immunosuppressive mice, improve the content of mice immune factors, enhance the antioxidant capacity, change the content of SCFAs, upregulate Fc $\gamma$ RIII and PKC- $\alpha$ protein expression, promote energy metabolism, balance the flora composition, maintain intestinal health, and play a role of immune regulation. Based on the results of this study, we will further explore the targeting role of the polysaccharides in immune-related metabolic pathways, and the regulation mechanism of probiotic Akkermansia on immunity.

\section{Data Availability}

The data used to support the findings of this study are included within the article.

\section{Conflicts of Interest}

All the authors declare that there is no conflict of interests regarding the publication of this paper.

\section{Authors' Contributions}

Huimin Jiang and Jinmei Wang contributed equally to this work.

\section{Acknowledgments}

We would like to thank all participants in the study. This work is supported by the Research Unit of Digestive Tract
Microecosystem Pharmacology and Toxicology, Chinese Academy of Medical Sciences and the CAMS Innovation Fund for Medical Sciences (2019-I2M-5-055).

\section{References}

[1] D. Blau, "Contributions to the psychobiology of aging," Psychosomatic Medicine, vol. 29, no. 2, pp. 194-195, 1967.

[2] R. J. Vagnozzi, M. Maillet, M. A. Sargent et al., “An acute immune response underlies the benefit of cardiac stem cell therapy," Nature, vol. 577, no. 7790, pp. 405-409, 2020.

[3] A. T. Springer, "Adhesion receptors of the immune system," Nature, vol. 346, no. 6283, pp. 425-434, 1990.

[4] J. P. Bourgault, K. R. Trabbic, M. Shi, and P. R. Andreana, "Synthesis of the tumor associative $\alpha$-aminooxy disaccharide of the TF antigen and its conjugation to a polysaccharide immune stimulant," Organic \& Biomolecular Chemistry, vol. 12, no. 11, pp. 1699-1702, 2014.

[5] T. Ohta, K. Kusano, A. Ido, C. Miura, and T. Miura, "Silkrose:: a novel acidic polysaccharide from the silkmoth that can stimulate the innate immune response," Carbohydrate Polymers, vol. 136, pp. 995-1001, 2016.

[6] S. Zhang, S. Nie, D. Huang, J. Huang, Y. Feng, and M. Xie, “A polysaccharide from Ganoderma atrum inhibits tumor growth by induction of apoptosis and activation of immune response in CT26-bearing mice," Journal of Agricultural and Food Chemistry, vol. 62, no. 38, pp. 9296-9304, 2014.

[7] Y. Wu, Y. Y. Li, C. Liu et al., "Structural characterization of an acidic Epimedium polysaccharide and its immuneenhancement activity," Carbohydrate Polymers, vol. 138, pp. 134-142, 2016.

[8] Y. Y. Niu, J. Dong, H. M. Jiang et al., "Effects of polysaccharide from Malus halliana Koehne flowers in cyclophosphamideinduced immunosuppression and oxidative stress on mice," Oxidative medicine and, cellular longevity, vol. 2020, pp. 110, 2020.

[9] P. R. Desai, H. Tegtmeyer, G. F. Springer, S. Metcalfe, and R. J. Svvennsen, "Intestinal flora, carcinomata and erythrocytes evoke anti-Tn antibodies," Naturwissenschaften, vol. 74, no. 5, pp. 247-248, 1987.

[10] L. Wen, R. E. Ley, P. Y. Volchkov et al., "Innate immunity and intestinal microbiota in the development of type 1 diabetes," Nature, vol. 455, no. 7216, pp. 1109-1113, 2008.

[11] K. Honda and K. Takeda, "Regulatory mechanisms of immune responses to intestinal bacteria," Mucosal Immunology, vol. 2, no. 3, pp. 187-196, 2009.

[12] K. C. Mountzouris, "Nutritional strategies targeting the beneficial modulation of the intestinal microflora with relevance to food safety: the role of probiotics and prebiotics," Food Safety, vol. 1, pp. 133-152, 2007.

[13] B. S. Bhardwaj, "Gut flora and its modification as a therapy," Reviews in Medical Microbiology, vol. 24, no. 3, pp. 52-54, 2013.

[14] S. Li, M. Li, H. Yue et al., "Structural elucidation of a pectic polysaccharide from Fructus mori and its bioactivity on intestinal bacteria strains," Carbohydrate Polymers, vol. 186, pp. $168-175,2018$.

[15] S. Sivaprakasam, P. D. Prasad, and N. Singh, "Benefits of shortchain fatty acids and their receptors in inflammation and carcinogenesis," Pharmacology \& Therapeutics, vol. 8, pp. 144151,2016 
[16] I. Kaji, T. Iwanaga, M. Watanabe et al., "SCFA transport in rat duodenum," American Journal of Physiology-Gastrointestinal and Liver Physiolog, vol. 308, no. 3, pp. G188-G197, 2015.

[17] G. Ma, B. M. Kimatu, L. Zhao, W. Yang, F. Pei, and Q. Hu, "In vivo fermentation of a Pleurotus eryngii polysaccharide and its effects on fecal microbiota composition and immune response," Food \& Function, vol. 8, no. 5, pp. 1810-1821, 2017.

[18] A. Pandey, "Proteomics to study genes and genomes," Nature, vol. 405, no. 6788, pp. 837-846, 2000.

[19] B. M. Gadella, "Sperm surface proteomics," Immune Infertility, W. Krause and R. Naz, Eds., pp. 33-48, Springer, Berlin, Heidelberg, 2017.

[20] J. Wang, D. Mauvoisin, E. Martin et al., "Nuclear proteomics uncovers diurnal regulatory landscapes in mouse liver," Cell Metabolism, vol. 25, no. 1, pp. 102-117, 2017.

[21] L. M. Li, S. Q. Yan, B. C. Lin, Q. Shi, and Y. Lu, "Single-cell proteomics for cancer immunotherapy," Advances in Cancer Research, vol. 139, pp. 185-207, 2018.

[22] X. Y. Wang, Proteomic and Metabolomic Studies of Dendrobium Huoshan Polysaccharide in the Intervention of Subacute Alcoholic Liver Injury in Mice, Hefei University of Technology, 2014.

[23] C. Ma, S.-H. Guan, M. Yang, X. Liu, and D.-A. Guo, "Differential protein expression in mouse splenic mononuclear cells treated with polysaccharides from spores of_Ganoderma lucidum_," Phytomedicine, vol. 15, no. 4, pp. 268-276, 2008.

[24] D. F. Wei, Proteomic Studies on the Immune Regulation and Anti-Tumor Effects of Astragalus Polysaccharide, Lanzhou University, 2012.

[25] Q. Yu, S. P. Nie, J. Q. Wang et al., "Chemoprotective effects of _Ganoderma atrum_ polysaccharide in cyclophosphamideinduced mice," International Journal of Biological Macromolecules, vol. 64, pp. 395-401, 2014.

[26] X. J. Wei, T. J. Hu, J. R. Chen, and Y. Y. Wei, "Inhibitory effect of carboxymethylpachymaran on cyclophosphamide-induced oxidative stress in mice," International Journal of Biological Macromolecules, vol. 49, no. 4, pp. 801-805, 2011.

[27] M. F. Mokhtar, E. H. A. Latib, S. Sufian, and K. Z. Ku Shaari, "Preparation of activated carbon from Durian shell and seed," Advanced Materials Research, vol. 626, pp. 887-891, 2012.

[28] K. Y. Foo and B. H. Hameed, "Textural porosity, surface chemistry and adsorptive properties of durian shell derived activated carbon prepared by microwave assisted $\mathrm{NaOH}$ activation," Chemical Engineering Journal, vol. 187, pp. 5362, 2012.

[29] S. Pongsamart and V. Lipipun, "Antimicrobial preparations using polysaccharide gel from durian fruit-rind," 2009, Patents, US20090149418.

[30] H. M. Jiang, J. Dong, S. Jiang et al., "Effect of_Durio zibethinus_rind polysaccharide on functional constipation and intestinal microbiota in rats," Food Research International, vol. 136, p. 109316, 2020.

[31] M. Z. Wu, G. Xie, Y. X. Li et al., "Cough-relieving, analgesic and antibiotic effects of durian shell extracts: a study in mice," Journal of Southern Medical University, vol. 30, no. 4, pp. 793797, 2010.

[32] Q. Guo, "Advances of immune checkpoint inhibitors in tumor immunotherapy," IOP Conference Series: Materials Science and Engineering, vol. 301, p. 012020, 2018.

[33] M. Ruslan, "Recognition of microorganisms and activation of the immune response," Nature, vol. 449, no. 7164, pp. 819826, 2007.
[34] M. E. Selsted and A. J. Ouellette, "Mammalian defensins in the antimicrobial immune response," Nature Immunology, vol. 6, no. 6, pp. 551-557, 2005.

[35] Y. Wang, Q. Qi, A. Li et al., "Immuno-enhancement effects of Yifei Tongluo Granules on cyclophosphamide- induced immunosuppression in Balb/c mice," Journal of Ethnopharmacology, vol. 194, pp. 72-82, 2016.

[36] H. J. Suh, H. S. Yang, K. S. Ra et al., "Peyer's patch-mediated intestinal immune system modulating activity of pectic-type polysaccharide from peel of Citrus unshiu," Food Chemistry, vol. 138, no. 2-3, pp. 1079-1086, 2013.

[37] F. Huang, R. F. Zhang, Y. J. Liu et al., "Dietary litchi pulp polysaccharides could enhance immunomodulatory and antioxidant effects in mice," International Journal of Biological Macromolecules, vol. 92, pp. 1067-1073, 2016.

[38] N. V. Belska, A. M. Guriev, M. G. Danilets et al., "Water-soluble polysaccharide obtained from _Acorus calamus_ L. classically activates macrophages and stimulates Th1 response," International Immunopharmacology, vol. 10, no. 8, pp. 933$942,2010$.

[39] J. du, H. Zhu, P. Liu et al., "Immune responses and gene expression in hepatopancreas from _Macrobrachium rosenbergii_ challenged by a novel pathogen spiroplasma MR1008," Fish \& Shellfish Immunology, vol. 34, no. 1, pp. 315323, 2013.

[40] X. Chen, J. Lu, Y. Zhang et al., "Studies of macrophage immuno-modulating activity of polysaccharides isolated from Paecilomyces tenuipes," International Journal of Biological Macromolecules, vol. 43, no. 3, pp. 252-256, 2008.

[41] J. J. Burns, L. Zhao, E. W. Taylor, and K. Spelman, “The influence of traditional herbal formulas on cytokine activity," Toxicology, vol. 278, no. 1, pp. 140-159, 2010.

[42] C. Tang, J. Sun, B. Zhou et al., "Effects of polysaccharides from purple sweet potatoes on immune response and gut microbiota composition in normal and cyclophosphamide treated mice," Food \& Function, vol. 9, no. 2, pp. 937-950, 2018.

[43] W. Liao, J. X. Lin, and W. J. Leonard, "IL-2 family cytokines: new insights into the complex roles of IL-2 as a broad regulator of T helper cell differentiation," Current Opinion in Immunology, vol. 23, no. 5, pp. 598-604, 2011.

[44] T. Hu, Q. Huang, K. Wong, and H. Yang, "Structure, molecular conformation, and immunomodulatory activity of four polysaccharide fractions from Lignosus rhinocerotis sclerotia," International Journal of Biological Macromolecules, vol. 94, no. Part A, pp. 423-430, 2017.

[45] A. Kumar, L. Rani, S. T. Mhaske et al., "IL-3 receptor expression on activated human Th cells is regulated by IL-4, and IL-3 synergizes with IL-4 to enhance Th2 cell differentiation," The Journal of Immunology, vol. 204, no. 4, pp. 819-831, 2020.

[46] A. E. Zanno, M. A. Romer, L. Fox et al., "Reducing Th2 inflammation through neutralizing IL-4 antibody rescues myelination in IUGR rat brain," Journal of Neurodevelopmental Disorders, vol. 11, no. 1, p. 34, 2019.

[47] Z. H. Gong, J. R. Hu, Y. Q. Duan et al., "Effects of Bletilla baicalensis polysaccharide on serum IL-2R, IL-4 and caspase- 8 expression in stomach tissue of model rats with gastric ulcer," Journal of Traditional Chinese Medicine, vol. 26, pp. 35-39, 2019.

[48] U. Gupta, S. K. Hira, R. Singh, A. Paladhi, P. Srivastava, and P. Pratim Manna, "Essential role of TNF- $\alpha$ in gamma c cytokine aided crosstalk between dendritic cells and natural killer 
cells in experimental murine lymphoma," International Immunopharmacology, vol. 78, p. 106031, 2020.

[49] A.-C. Voirin, N. Perek, and F. Roche, "Inflammatory stress induced by a combination of cytokines (IL-6, IL-17, TNF- $\alpha$ ) leads to a loss of integrity on bEnd.3 endothelial cells _in vitro_ BBB model," Brain Research, vol. 1730, p. 146647, 2020.

[50] R. P. da Silva, I. Nissim, M. E. Brosnan, and J. T. Brosnan, "Creatine synthesis: hepatic metabolism of guanidinoacetate and creatine in the rat in vitro and in vivo," American Journal of Physiology-Endocrinology and Metabolism, vol. 296, p. E256, 2009.

[51] R. Bahirwani and K. Reddy, "Drug-induced liver injury due to cancer chemotherapeutic agents," Seminars in Liver Disease, vol. 34, no. 2, pp. 162-171, 2014.

[52] X. J. Li, B. Li, and Y. Jia, "The hepatoprotective effect of Haoqin Qingdan decoction against liver injury induced by a chemotherapeutic drug cyclophosphamide," Evidence-Based Complementary and Alternative Medicine, vol. 2015, Article ID 978219, 8 pages, 2015.

[53] B. A. Baldo and N. H. Pham, "Adverse reactions to targeted and non-targeted chemotherapeutic drugs with emphasis on hypersensitivity responses and the invasive metastatic switch," Cancer and Metastasis Reviews, vol. 32, no. 3-4, pp. 723-761, 2013.

[54] X. F. Xu and X. Zhang, "Effects of cyclophosphamide on immune system and gut microbiota in mice," Microbiological Research, vol. 171, pp. 97-106, 2015.

[55] D. M. Yang, J. Q. Zhang, and Y. F. Fei, "Lycium barbarumpolysaccharide attenuates chemotherapy-induced ovarian injury by reducing oxidative stress," Journal of Obstetrics and Gynaecology Research, vol. 43, no. 10, pp. 1621-1628, 2017.

[56] P. Luo, H. Z. Liu, X. Y. Le, H. Du, and X. H. Kang, "Squid ink polysaccharide prevents chemotherapy induced injury in the testes of reproducing mice," Pakistan journal of pharmaceutical ences, vol. 31, pp. 25-29, 2018.

[57] X. 1. Meng, L. Xue, Z. W. Zhang et al., "Effect of Portulaca oleracea polysaccharide on immunological function in mice with cyclophosphamide-induced immunosuppression," Chinese Journal of New Drugs, vol. 26, pp. 1296-1300, 2017.

[58] C. Ma, S.-H. Guan, M. Yang, X. Liu, and D.-A. Guo, "Differential protein expression in mouse splenic mononuclear cells treated with polysaccharides from spores of Ganoderma lucidum," Phytomedicine, vol. 15, pp. 268-276, 2008.

[59] J. V. Ravetch and B. Perussia, "Alternative membrane forms of Fc gamma RIII(CD16) on human natural killer cells and neutrophils. Cell type-specific expression of two genes that differ in single nucleotide substitutions," Journal of Experimental Medicine, vol. 170, no. 2, pp. 481-497, 1989.

[60] A. Coxon, X. Cullere, S. Knight et al., "Fc $\gamma$ RIII mediates neutrophil recruitment to immune Complexes," Immunity, vol. 14, no. 6, pp. 693-704, 2001.

[61] F. Nimmerjahn and J. V. Ravetch, "Fc $\gamma$ receptors as regulators of immune responses," Nature Reviews Immunology, vol. 8, no. 1, pp. 34-47, 2008.

[62] Y. Wang, J. Wu, R. Newton, N. S. Bahaie, C. Long, and B. Walcheck, "ADAM17 cleaves CD16b (Fc $\gamma$ RIIIb) in human neutrophils," Biochimica et Biophysica Acta, vol. 1833, no. 3, pp. 680-685, 2013.

[63] R. Romee, B. Foley, T. Lenvik et al., "NK cell CD16 surface expression and function is regulated by a disintegrin and metalloprotease-17 (ADAM17)," Blood, vol. 121, no. 18, pp. 3599-3608, 2013.

[64] A. Roghanian, G. Hu, C. Fraser et al., "Cyclophosphamide enhances cancer antibody immunotherapy in the resistant bone marrow niche by modulating macrophage Fc $\gamma$ R expression," Cancer Immunology Research, vol. 7, no. 11, pp. 18761890, 2019.

[65] S. Das, O. Bhattacharjee, and A. Goswami, "Arabinosylated lipoarabinomannan (Ara-LAM) mediated intracellular mechanisms against tuberculosis infection: involvement of protein kinase C (PKC) mediated signaling," Tuberculosis, vol. 95, no. 2, pp. 208-216, 2015.

[66] M. Faseleh Jahromi, P. Shokryazdan, Z. Idrus, R. Ebrahimi, F. Bashokouh, and J. B. Liang, "Modulation of immune function in rats using oligosaccharides extracted from palm kernel cake," BioMed Research International, vol. 2017, Article ID 2576921, 10 pages, 2017.

[67] G. Baier and J. Wagner, "PKC inhibitors: potential in T celldependent immune diseases," Current Opinion in Cell Biology, vol. 21, no. 2, pp. 262-267, 2009.

[68] N. Perera, F.-L. Yang, Y.-T. Lu, L.-H. Li, K.-F. Hua, and S.H. Wu, "Antrodia cinnamomeaGalactomannan elicits immuno-stimulatory activity through toll-like receptor 4," International journal of biological sciences, vol. 14, no. 10, pp. 1378-1388, 2018.

[69] A. Rehman, P. Lepage, A. Nolte, S. Hellmig, S. Schreiber, and S. J. Ott, "Transcriptional activity of the dominant gut mucosal microbiota in chronic inflammatory bowel disease patients," Journal of Medical Microbiology, vol. 59, no. 9, pp. 1114$1122,2010$.

[70] C. G. Zhang, W. J. Gong, Z. H. Li, D. W. Gao, and Y. Gao, "Research progress of gut flora in improving human wellness," Food Science and Human Wellness, vol. 8, no. 2, pp. 102-105, 2019.

[71] W. Xia, L. Z. Ke, L. Li, G. Wei, and F. Xu, "Clinical efficacy of probiotics for recurrent respiratory tract infections of children and its influence on immune function: a systematic review," Drug evaluation study, vol. 43, pp. 140-146, 2020.

[72] G. Q. Wang, H. Y. Tang, Y. Zhang, X. Xiao, and Y. J. Xia, "The intervention effects of _Lactobacillus casei_LC2W on _Escherichia coli_ O157:H7 -induced mouse colitis," Food Science and Human Wellness, vol. 9, no. 3, pp. 289-294, 2020.

[73] S. Li, M. Li, H. Yue et al., "Structural elucidation of a pectic polysaccharide from _Fructus Mori_ and its bioactivity on intestinal bacteria strains," Carbohydrate Polymers, vol. 186, pp. 168-175, 2018.

[74] X. Wu, L. Zhou, X. Luo, X. L. Deng, R. Y. Wen, and J. W. Wu, "Effect of polysaccharide of Sijunzi decoction on gut flora and immune function in spleen-deficiency mice," Pharmacology and Clinics of Chinese Materia Medica, vol. 2, pp. 12-14, 2014.

[75] D. W. Cockburn and N. M. Koropatkin, "Polysaccharide degradation by the intestinal microbiota and its influence on human health and disease," Journal of Molecular Biology, vol. 428, no. 16, pp. 3230-3252, 2016.

[76] H. J. Flint, K. P. Scott, P. Louis, and S. H. Duncan, “The role of the gut microbiota in nutrition and health," Nature Reviews Gastroenterology \& Hepatology, vol. 9, no. 10, pp. 577-589, 2012.

[77] P. J. Turnbaugh, R. E. Ley, M. A. Mahowald, V. Magrini, E. R. Mardis, and J. I. Gordon, "An obesity-associated gut 
microbiome with increased capacity for energy harvest," Nature, vol. 444, no. 7122, pp. 1027-1031, 2006.

[78] M. G. Gareau, P. M. Sherman, and W. A. Walker, "Probiotics and the gut microbiota in intestinal health and disease," Nature Reviews Gastroenterology \& Hepatology, vol. 7, no. 9, pp. 503-514, 2010.

[79] M. Delzenne, A. M. Neyrinck, F. Bäckhed, and P. D. Cani, "Targeting gut microbiota in obesity: effects of prebiotics and probiotics," Nature Reviews Endocrinology, vol. 7, no. 11, pp. 639-646, 2011.

[80] B. Seo, K. Jeon, S. Moon et al., “_Roseburia_spp. Abundance Associates with Alcohol Consumption in Humans and Its Administration Ameliorates Alcoholic Fatty Liver in Mice," Cell Host \& Microbe, vol. 27, no. 1, pp. 25-40.e6, 2020.

[81] Y. L. Feng, J. Zhu, and R. Sensenstein, "Development of a headspace solid-phase microextraction method combined with gas chromatography mass spectrometry for the determination of phthalate esters in cow milk," Analytica Chimica Acta, vol. 538, no. 1-2, pp. 41-48, 2005.

[82] D. Rachel, "Regulatory T cells: a helping hand from Bacteroides fragilis," Nature Reviews Immunology, vol. 10, p. 539, 2010.

[83] E. Hosseini, C. Grootaert, W. Verstraete, and T. van de Wiele, "Propionate as a health-promoting microbial metabolite in the human gut," Nutrition Reviews, vol. 69, no. 5, pp. 245-258, 2011.

[84] H. Ursula, "Microbiome: pro-inflammatory Prevotella?," Nature Reviews Microbiology, vol. 12, p. 5, 2014.

[85] D. A. Relman, "How to build healthy growth-promoting gut communities," Nature Reviews Gastroenterology \& Hepatology, vol. 13, no. 7, pp. 379-380, 2016.

[86] M. Sakamoto, M. Umeda, I. Ishikawa, and Y. Benno, "Prevotella multisaccharivorax sp. nov., isolated from human subgingival plaque," International Journal of Systematic and Evolutionary Microbiology, vol. 55, no. 5, pp. 1839-1843, 2005.

[87] M. Derrien, "Akkermansia muciniphila gen. nov. sp. nov. a human intestinal mucin-degrading bacterium," International Journal of Systematic \& Evolutionary Microbiology, vol. 54, no. 5, pp. 1469-1476, 2004.

[88] A. Everard, C. Belzer, L. Geurts et al., "Cross-talk between Akkermansia muciniphila and intestinal epithelium controls diet-induced obesity," Proceedings of the National Academy of Sciences, vol. 110, no. 22, pp. 9066-9071, 2013.

[89] M. C. Dao, A. Everard, J. Aron-Wisnewsky et al., "Akkermansia muciniphila and improved metabolic health during a dietary intervention in obesity: relationship with gut microbiome richness and ecology," Gut, vol. 65, no. 3, pp. 426-436, 2016.

[90] C. D. Owen, L. E. Tailford, S. Monaco et al., "Unravelling the specificity and mechanism of sialic acid recognition by the gut symbiont_Ruminococcus gnavus_," Nature Communications, vol. 8, no. 1, p. 2196, 2017.

[91] S. Fukuda, H. Toh, K. Hase et al., “Bifidobacteria can protect from enteropathogenic infection through production of acetate," Nature, vol. 469, no. 7331, pp. 543-547, 2011.

[92] T. Konikoff and U. Gophna, “_Oscillospira_ : a Central, Enigmatic Component of the Human Gut Microbiota," Trends in Microbiology, vol. 24, no. 7, pp. 523-524, 2016.

[93] U. Gophna, T. Konikoff, and H. B. Nielsen, "Oscillospira and related bacteria-from metagenomic species to metabolic features," Environmental Microbiology, vol. 19, no. 3, pp. 835841, 2017. 